ISSN: 0213-2079 - ISSN electrónico: 2386-3889

DOI: https://doi.org/10.14201/shhmo20194123569

\title{
EL SACRAMENTO OLVIDADO: LA CONFIRMACIÓN EN LA ARCHIDIÓCESIS DE SANTIAGO, FINES DEL XVI A 1833
}

\author{
The forgotten sacrament: Confirmation in the Archidiocese \\ of Santiago, end of the 16th century to 1833
}

\section{Ofelia REY CASTELAO}

Facultad de Geografía e Historia. Universidade de Santiago de Compostela

Correo-e: ofelia.rey@usc.es

\section{Rubén CASTRO REDONDO}

Universidad de Cantabria

Correo-e: ruben.castro@unican.es

Fecha de envío: 15 de octubre de 2019

Fecha de aceptación: 19 de noviembre de 2019

RESUMEN: La confirmación es el sacramento al que la Iglesia católica dio menos importancia en la Contrarreforma al no considerarlo necesario para la salvación y encomendarlo solo a los obispos. Esto ha generado la idea de un general descuido en su cumplimiento por lo que en este artículo estudiamos la aplicación real de este sacramento en la archidiócesis de Santiago de Compostela, la tercera en importancia de la Corona de Castilla, muy poblada y de gran tamaño, lo que dificultaba su visita por parte de los arzobispos. Para este objetivo utilizamos textos normativos y sobre todo, cientos de listas de confirmados, lo que nos ha permitido datar, medir y diagnosticar la atención a este sacramento y de modo especial, analizar los importantes cambios que se produjeron en el tránsito de la Edad Moderna 
OFELIA REY CASTELAO Y RUBÉN CASTRO REDONDO

EL SACRAMENTO OLVIDADO: LA CONFIRMACIÓN

EN LA ARCHIDIÓCESIS DE SANTIAGO, FINES DEL XVI A 1833

a la Contemporánea, cuando se percibió la capacidad de la confirmación para reafirmar un poder episcopal en crisis.

Palabras clave: confirmación; sacramento; archidiócesis de Santiago; listas.

ABSTRACT: Confirmation is the sacrament to which the Catholic Church gave less importance in the Counter-Reformation by not considering it necessary for salvation and entrusting it only to bishops. This has generated the idea of a general careless in its fulfilment, so in this paper we study the real application of this sacrament in the archdiocese of Santiago de Compostela, the third in importance of the Crown of Castile, very populated and large, making it difficult to visit by the archbishops. For this purpose we use normative texts and above all, hundreds of confirmed lists, which has allowed us to date, measure and diagnose the attention to this sacrament and in a special way, analyse the important changes occurred in the transit of the Early Modern Age to the Contemporary Age, when the capacity of the confirmation to reaffirm an episcopal power in crisis was perceived.

Keywords: confirmation; sacrament; archdiocese of Santiago; lists.

\section{INTRODUCCIÓN}

La confirmation: un sacrement oublié? Así se tituló un coloquio celebrado en París en 20191. En lo referente a España sobraría el interrogante porque, desde el punto de vista histórico, apenas se ha estudiado. Exceptuando las publicaciones teológicas, la salvedad está en trabajos de demografía histórica que hace años emplearon las listas de confirmados para medir la mortalidad infantil-juvenil y en otros dedicados a las visitas pastorales en los que se hace referencia a la práctica de la confirmación. Son pocas las aportaciones específicas, como la de Dedieu sobre los sínodos y expedientes inquisitoriales de la diócesis de Toledo en el siglo XVI, para demostrar el elevado grado de cumplimiento de este sacramento (Dedieu, 1979: 261-294), o las de García Fernández al referirse a los ritos de paso juveniles en Valladolid (García, 2019: 50-53). De la bibliografía extranjera, el dominio es de Italia, centrado en la relación entre las visitas pastorales y la confirmación (Carr: 2007), sin entrar en la práctica; Francia no ha abordado este tema, por la especificidad de

1. Centre Roland Mousnier, París, 28-6-2019. Allí hemos hecho un avance: Rey Castelao, O. y Castro Redondo, R., «Le parrainage de confirmation en Galice du XVIe au XIXe siècles». 
OFELIA REY CASTELAO Y RUBÉN CASTRO REDONDO

EL SACRAMENTO OLVIDADO: LA CONFIRMACIÓN

EN LA ARCHIDIÓCESIS DE SANTIAGO, FINES DEL XVI A 1833

su modelo religioso en el que la primera comunión se impuso como ceremonia de acceso al uso de razón y como rito parroquial por antonomasia (Delumeau, 1987; Vénard, 1997: 898; Heywood, 2018: 25).

La deficiencia bibliográfica refleja el hecho de que la confirmación fue el sacramento menos atendido por los obispos. La Iglesia católica en el concilio de Trento dejó clara su condición y su calidad sacramental — «cosa que nadie ha dudado sino los enemigos del orden episcopal», decía el arzobispo Martini de Florencia en $1785^{2}-$, como espejo del bautismo, pero no lo declaró necesario para la salvación y, dado que los obispos eran sus únicos ministros posibles, todo dependió de la implicación de estos. Al papa tocaba, en última instancia, hacer el seguimiento de los obispos, pero el control se limitaba a las visitas ad limina, más retóricas que reales (Barreiro, 1990: 489-515).En cuanto a los párrocos, no eran responsables de su impartición sino solo de preparar y advertir a sus feligreses de la conveniencia y oportunidad de recibirlo, y menos todavía lo eran los fieles, que solo podían confirmarse si el obispo cumplía su función y la facilitaba con su presencia en las parroquias. Todo lo cual se tradujo en desidia por parte de los curas - visible en el mal registro de las confirmaciones - y por parte de los fieles, que no se veían compelidos a cumplirlo salvo en el caso de los hombres que aspirasen a la tonsura.

Así pues, la aplicación real de la confirmación recaía solo en el obispo y dependía de sus condiciones personales y de las circunstancias de las diócesis que lo hicieran con mayor o menor asiduidad, así como de la costumbre, aludida en casi todos los textos que se ocuparon de este sacramento. Expuestas así las cosas, puede parecer que la confirmación, desde el punto de vista religioso, no tuvo un papel relevante en la Contrarreforma (Morgado, 2008: 23). Sin embargo, como veremos, adquirió una importancia creciente, sobre todo en el tránsito de la Edad Moderna a la Contemporánea, cuando la vistosidad de las ceremonias multitudinarias se utilizó por los obispos como un instrumento para hacerse ver y para demostrar su poder, justo cuando este era cuestionado. Para comprobarlo, apenas entraremos en debates teológicos, sino en la práctica de la confirmación en la archidiócesis de Santiago, la tercera en importancia de la Corona de Castilla, desde finalizado el Concilio de Trento hasta 1835, cuando el arzobispo fray Rafael Vélez y su auxiliar fueron desterrados después de ser sometidos a juicio en 1833 por los liberales, dos hechos simbólicos del final del Antiguo Régimen ${ }^{3}$.

2. Antonio Martini, Instrucciones morales sobre los sacramentos de la Iglesia, Barcelona, s.i., 1817 , p. 40 (1 1785$)$.

3. Investigación realizada en el proyecto Culturas urbanas y resistencias en la monarquía hispánica en la Edad Moderna, referencia PGC2018-093841-B-C31 (2019-2021) financiado por la Agencia Estatal de Investigación (Ministerio de Ciencia e Innovación) y Fondos FEDER (Unión Europea). 
OFELIA REY CASTELAO Y RUBÉN CASTRO REDONDO

EL SACRAMENTO OLVIDADO: LA CONFIRMACIÓN

EN LA ARCHIDIÓCESIS DE SANTIAGO, FINES DEL XVI A 1833

\section{LA NORMATIVA Y SUS INTÉRPRETES}

Los textos básicos derivados de Trento - pontifical romano de 1595, ceremonial de 1600 y ritual de 1644 - son poco explícitos sobre la impartición de la confirmación. El catecismo de Pío V (1566) denuncia que «muchos abandonan del todo este sacramento y hay poquísimos que procuren sacar provecho de él» y que «muchas veces acaece andar los fieles o muy apresurados o muy descuidados y perezosos acerca de recibir este sacramento", insistiendo al clero que predicase su valor, en especial en Pascua y Pentecostés - el período religioso más apropiado para su celebración-, argumentando la diferencia entre el bautismo, que «tiene la virtud de regenerar» y la confirmación, que serviría para «crecer o infundir robustez en las almas» y para fortalecerse «con más armas muy seguras para bajar al combate espiritual, cuya corona es la vida eterna», de modo que si bien «no es tan necesario que no puedan sin él salvarse las almas... ninguno debe dejarle». Obligación de obispos y párrocos era declarar «quiénes de qué edad y con qué disposición deben venir», indicando que «no es lo más conveniente darlo a los niños antes de que tengan uso de razón. Y así si no pareciere que deba dilatarse hasta los doce años, por lo menos hasta los siete»; los adultos deberían acudir con fe, devoción y dolor de los pecados, habiendo confesado, ayunado y hecho obras de piedad a una ceremonia en la que se les impondría el crisma en presencia de un padrino ${ }^{4}$. En el pontifical se reconocía que era imposible abarcar una diócesis en el tiempo canónico, por lo que se ordenó a los obispos que lo administrasen durante las visitas y siempre que lo creyeran oportuno; es decir: se dejaba muy abierta esta opción.

La normativa no pasaba de recomendar y esto generó diversas interpretaciones, entre las que destaca la del arzobispo de Milán, Carlos Borromeo: de hecho, sus biógrafos afirmaban que hasta él «estaba como olvidado el conocimiento de este sacramento» ${ }^{5}$. En sus instrucciones(1599), Borromeo endureció la normativa papal, incidiendo en que el jefe de casa «tenga cuidado de que sus hijos y familia reciban a su tiempo el sacramento... para que no haya alguno en su casa que no esté confirmado», y, de no hacerlo, si el hijo muriera sin confirmar «harán penitencia tres años» amonestando a los párrocos para que averiguasen si los enfermos graves estaban confirmados y si «hay obispo, haga que lo confirme ${ }^{6}$, lo que equivale a no decir nada. Estas instrucciones, publicadas en castellano en 1770, se reeditaron en varias ocasiones y llegaron con facilidad a Santiago (Domato, 2017: 136-137).

Hay que esperar al papado de Benedicto XIV para encontrar una reivindicación de la confirmación -él mismo confirmaba asiduamente en Roma-, en su

4. Catecismo del Santo concilio de Trento para los párrocos ordenado por disposición de san Pio V, traducido (1ª 1761), I, Barcelona, Sierra y Martín, 1833, pp. 188-197.

5. Luis Muñoz, Vida de San Carlos Borromeo, Madrid, Imprenta Real, 1626, p. 35.

6. Instrucciones de S. Carlos Borromeo sobre la administración del sacramento, Madrid, J. Ibarra, 1768, pp. 43, 154 y 189. 
OFELIA REY CASTELAO Y RUBÉN CASTRO REDONDO

EL SACRAMENTO OLVIDADO: LA CONFIRMACIÓN

EN LA ARCHIDIÓCESIS DE SANTIAGO, FINES DEL XVI A 1833

encíclica Et si minime de 1742, advirtiendo a los obispos que no se confirmase a quienes no conociesen el fundamento de la doctrina y el valor de los sacramentos, e instándolos a visitar las diócesis para impartirla, predicar y dar ejemplo «como señor de los ejércitos, lo que es casi una ley». Este papa - Próspero Lambertini de nacimiento - se había explayado más en las instrucciones que dictó en 1732 como obispo de Bolonia, cuya traducción al castellano en 1751 tuvo muchas ediciones. Su interés radica no solo en que los arzobispos de Santiago las conocieron, sino que reflejan una realidad similar a la que estos encontraban en la Galicia occidental. En ese texto práctico, Lambertini recordaba a su clero que la confirmación es un sacramento instituido por Cristo y que Trento condenaba a quien lo negase, y que mientras la gracia del bautismo es regenerante, la de la confirmación es gratificante, corroborante y confortante «para entrar en el rudo fuerte combate que nos queda en la mocedad, virilidad y senectud de la vida espiritual». Sin embargo, decía que en su diócesis «hay muchísimos que nada cuidan de venir a buscar este sacramento, en consecuencia de una proposición verdadera pero muy mal aplicada: y es que sin este sacramento se pueden salvar». Explicaba que era así para los niños pero no para los adultos, por precepto divino, en época de persecución de tiranos, cuando alguno se hallase sometido a tentaciones contra la fe o en peligro de muerte, «y comete pecado mortal el que por desprecio o por negligencia supina, no solicita fortalecer su alma con la gracia», de lo que eran reos los curas, padres, madres, tutores y amos que no hicieran confirmar a los suyos; además, asumía el mandato de Borromeo de que, al ser sacramento de vivos, para recibirlo había que tener la inocencia del bautismo o la obtenida con la penitencia ${ }^{7}$. Lo que más nos interesa es su experiencia pastoral, que veremos más adelante. La normativa romana no añadió nada en el resto del XVIII hasta la instrucción de la Congregación de Propaganda Fide de 4-5-1774, documento que solo reforzaba el valor de la confirmación (Ribas, 1969: 403-439).

Por lo que respecta a los tratados de moral más conocidos, salvo en que era sacramento, no hay acuerdo en nada. Por ejemplo, H. Busembaum (1645) insiste, remitiéndose a Suárez y a Navarro, en que «la Iglesia no obliga con penas algunas a recivirlo: como porque no se infiere tal precepto, ni de las Escrituras ni de la tradición ni del fin o institución de este sacramento», por lo que peca solo quien lo desprecia, y en que todo lo demás era igual de opinable - edades, lugares de la ceremonia, tiempos, obligaciones de los padrinos, etc. $-\mathrm{y}$ casi nada punible, como era de esperar en un autor jesuítico ${ }^{8}$. De este laxismo no se alejaba mucho Antonio Diana en su muy difundida suma (1644) ${ }^{9}$.El capuchino fray Jaime Corella (1702), que

7. Pastoral de N.S.P. Benedicto XIV... siendo cardenal arzobispo de la S.I. de Bolonia... e Instrucciones... para su diócesis (1 $\left.1^{\mathrm{a}} 1732\right)$, empleamos la $6^{\mathrm{a}}$ ed. de Madrid, 1789, pp. 25-39.

8. Hermann Busembaum, Médula de teología moral, Barcelona, José Andreu, 1674, pp. 340-344.

9. Antonio Diana, Suma. Diana Recopilado en romance, ed. de Madrid, Melchor Sánchez, 1657, pp. 188-198. 
OFELIA REY CASTELAO Y RUBÉN CASTRO REDONDO

EL SACRAMENTO OLVIDADO: LA CONFIRMACIÓN

EN LA ARCHIDIÓCESIS DE SANTIAGO, FINES DEL XVI A 1833

tenía experiencia por haber ido en misión con el obispo de Pamplona Juan Grande en las confirmaciones, opinaba que al no ser necesario, «no será pecado mortal no recibirlo» salvo por menosprecio, escándalo o en peligro de la fe, «ni es pecado venial no recibirlo habiendo oportunidad». Su mayor insistencia está en que solo el obispo puede oficiar, «y si en esto es negligente mucho tiempo peca fatalmente». También pecaba el obispo que lo administrase en obispado ajeno sin permiso del titular, aunque sería válido para quien lo recibiere «porque como sacramento no pende de la jurisdicción del propio ordinario», y el obispo que en su mismo obispado confirmase a feligreses de otro. No pecaría al hacerlo fuera de la iglesia, en su palacio y en otros lugares decentes, o en un día de fiesta o de trabajo y aunque fuese en tiempo de entredicho. Corella daba por supuesto que se confirmaba a los niños sin uso de razón, de los que no se esperaba intención para recibirlo, en tanto que los obispos harían santamente si ordenaban a los curas que confesasen a los adultos que lo recibiesen ${ }^{10}$.

El muy difundido Prontuario del dominico fray Francisco Larraga (1706) es escueto, pero se pronuncia contra quienes declaraban que la confirmación «solo es de consejo» y considera que «es mucho más fundada y al presente casi cierta proposición» que la hacía necesaria, tanto por las normas como sobre todo por «la común tradición y consentimiento de los PP y Concilios y de la práctica universal de la Iglesia». Las ediciones tardías recogen ya las instrucciones de Lambertini y solo señalan que el sujeto es el fiel vivo, párvulo o adulto según fuera la costumbre del obispado ${ }^{11}$. Otro texto recurrente, el del franciscano observante fray Francisco Echarri (1728) señala que los obispos electos no podían confirmar y justifica la $b o f e-$ tada o toque ritual al confirmando "para que entienda que debe padecer injurias en defensa de la fe y para que se vista de la paciencia de Cristo y también para que se acuerde» y no vuelva una segunda vez. En la revisión de fray Antonio López Muñoz, OP (1769) se matiza que los fieles que no se confirman pecarán más o menos según fuera su negligencia y descuido y que se debe aguardar a que el confirmando sepa discernir entre bautismo y confirmación, de no haber causa justa para anticiparlo ${ }^{12}$.

En Santiago, la normativa es muy sucinta, tanto porque lo dictado en Trento se recogió tal cual en el concilio provincial de Salamanca 1565-66-, como porque se dejaba a criterio de los arzobispos. Las primeras constituciones sinodales postridentinas, las de 1576 del arzobispo Francisco Blanco de Salcedo, publicadas en

10. Fray Jaime Corella, Suma de theologia moral, Barcelona, José LLopis, 1702, pp. 260-263, 265.

11. Fray Francisco Larraga, Prontuario de teología moral, J.J. Ezquerro, Pamplona, 1706, la tercera, de 1780 , pp. $68-70$.

12. Fray Francisco Echarri, Directorio espiritual, Pamplona, 1728, usamos edición de 1769, pp. 93 y 182-192. 
OFELIA REY CASTELAO Y RUBÉN CASTRO REDONDO

EL SACRAMENTO OLVIDADO: LA CONFIRMACIÓN

EN LA ARCHIDIÓCESIS DE SANTIAGO, FINES DEL XVI A 1833

$1601^{13}$, ordenan a los rectores que cuando supieran que los prelados iban a visitar sus iglesias, amonestasen a sus feligreses adultos para recibir el sacramento, y para esto procurasen «estar confesados o al menos contritos de sus pecados», conscientes de «lo mucho que le deven estimar y la piedad y religión con que a él se han de allegar y la culpa que incurrirán los que en esto fueran negligentes»; además de recibirlo dignamente, estando limpias las vendas usadas en el rito. Los sínodos posteriores se limitaron a corroborar el de 1576 y nada aportó el de 1746 que lo sustituyó y que estuvo vigente hasta 1887.

Así pues, el documento más importante es la «instrucción» dirigida a los párrocos por el arzobispo Francisco Alejandro Bocanegra y Jivaja en 20-4-1774, recién llegado a Santiago. Es un breve impreso que «se guardará después en el archivo de la iglesia» ${ }^{14}$, basado en su experiencia como obispo de Guadix y que contiene párrafos de Lambertini, del catecismo romano y de Borromeo, es decir, textos rigoristas y defensores de la confirmación como reflejo y complemento del bautismo y como instrumento exclusivo de los obispos en un tiempo, el de la Ilustración, en el que estos defendían el episcopalismo y en el que la literatura jesuítica, la más laxa, como vimos, estaba en retirada. En todo caso, se inscribe en el sentido episcopalista de este prelado y de muchos otros de su época.

La instrucción recuerda a los adultos que deben saber lo que reciben en el sacramento para percibir «los preciosisimos i admirables Dones, que en él se comunican», denunciando que «se experimenta que muchos llegan a recibirlo con ignorancia mui crasa», por lo que era necesario instruirlos. Para esto, expone la «esencia, efectos i disposición del Sacramento» en forma de preguntas y respuestas, como el catecismo, afirmando que está «ordenado a la salvación» para que los cristianos recibieran la «firmeza, i fortaleza en la Fe que recibieron i profesaron en el Bautismo». Que el ministro es el obispo y lo hace ungiendo «en forma de Cruz la frente del que le recibe, con el Santo Crisma», invocando al misterio de la Trinidad, «para ser conocido el Cristiano por Soldado de la Milicia de nuestro Señor Jesucristo» y defensor de la fe. El crisma estaría protegido por una venda «para advertirle el cuidado i recato, que ha de tener en conservar la Fe» $\mathrm{y}$ «la humildad de entendimiento», creer los misterios de la fe sin «inquirir con vana curiosidad razón de lo que enseña», y soportar la «apretura de tribulaciones» para la conquista del cielo. Luego, el oficiante da «una leve percusión al confirmado i le anuncia paz», y le indica que debe estar dispuesto "para recibir i padecer injurias i afrentas por causa de la Fe», llegando al martirio.

13. Constituciones Sinodales del Arzobispado de Santiago, Santiago, Luis de Paz, 1601, p. 14.

14. Instrucción que los párrocos del arzobispado de Santiago deben observar en disponer sus feligreses para recibir fructuosamente el Santo Sacramento de la Confirmación. Archivo Histórico Diocesano de Santiago (AHDS), s.r. 
OFELIA REY CASTELAO Y RUBÉN CASTRO REDONDO

EL SACRAMENTO OLVIDADO: LA CONFIRMACIÓN

EN LA ARCHIDIÓCESIS DE SANTIAGO, FINES DEL XVI A 1833

El tono beligerante de Bocanegra está tomado de Pío V y de Lambertini, pero lo agudiza, subrayando que si en el bautismo «profesamos ser Soldados de Jesu-Cristo más en la Confirmación» y «somos armados, i puestos a punto de pelea para entrar en las batallas espirituales, que se ofrecen contra la Fe»-Bocanegra tenía cierta fijación con el islam-. A cambio, los confirmandos se benefician de los efectos de la confirmación: «causar gracia justificante, que constituye al hombre en ser amigo de Dios», «la gracia precipua» para resistir las tentaciones, los dones y gracias del Espíritu Santo e «imprimir carácter en el Alma», por lo que no se puede recibir dos veces. Finalmente, dado que se confirmaba a párvulos, se señala que no necesitaban intención, pero sí los adultos, y estar en gracia «confesándose o en acto de contrición», pero estando en pecado mortal, pecarían «con pecado de sacrilegio».

Dado que el texto de Bocanegra estaba destinado a instruir a los fieles, consideraba que era el padrino quien tenía «la obligación de enseñarle el Credo, Padre Nuestro, i Ave María», pero cesaba esa carga «si el confirmado tiene oportunidad para saberlo independientemente del Padrino». Se entiende pues que el párroco era el responsable, contemplando dos opciones: si este «tiene caudal de doctrina, puede hacerles la Plática en la forma que más apropósito juzgare»; de no tenerlo «i quando no quiera usar de otro estudio, puede leerles a la letra esta instrucción en voz clara, i pausada, para que cómodamente sea entendida». La cuestión es qué entendería de esa lectura una población con muy bajo nivel formativo - por entonces en la Galicia occidental solo iban a la escuela el $12.8 \%$ de los niños y el $1.5 \%$ de las niñas y apenas sabían firmar el $30 \%$ de los hombres y menos del $5 \%$ de las mujeres - , y que mayoritariamente hablaba gallego, además de tener poco contacto con el castellano; incluso parece difícil que la verbosidad teológica del prelado fuera entendida por los párrocos. La instrucción se centra luego en el ceremonial, lo que veremos más adelante.

\section{LAS CONFIRMACIONES EN LA TAREA PASTORAL}

Nos encontramos ante un sacramento un tanto difuso, que dependía de una sola persona por diócesis, ya que los papas nunca rebajaron la condición del oficiante, aun pudiendo habilitar a simples sacerdotes. La alternativa fue que la normativa se adaptase a la realidad y circunstancias de las diócesis y de sus titulares, que estos designasen obispos auxiliares y que la costumbre acabase conviviendo con la norma o la sustituyese. Se quiera o no, la práctica de la confirmación era una cuestión estadística complicada. En la diócesis de Santiago, como en muchas otras, el bautismo era administrado por un párroco por feligresía, en la que solía vivir, y en una que tuviera cien vecinos, serían unos $25 / 30$ bautizos al año, mientras que en la confirmación era un único oficiante - y/o su auxiliar - para más de mil parroquias en las que cada año nacían varios miles de niños y niñas a los que habría que confirmar; 
OFELIA REY CASTELAO Y RUBÉN CASTRO REDONDO

EL SACRAMENTO OLVIDADO: LA CONFIRMACIÓN

EN LA ARCHIDIÓCESIS DE SANTIAGO, FINES DEL XVI A 1833

el arzobispo vivía lejos - entre Compostela y los extremos de la diócesis hay entre ochenta y cien kilómetros - y tenía muchas otras funciones de primer nivel, ya no solo el gobierno de la diócesis, sino el de la provincia eclesiástica de Santiago, además de ser el señor de la ciudad de Compostela y del mayor señorío de Galicia, atender a cuestiones de protocolo y representación y concurrir a lo que requiriesen el rey u otras autoridades, incluso el papa.

Más allá de otros problemas, las cifras eran el más grave, por cuanto la población de la diócesis creció mucho - 191.500 habitantes en 1591, 573.638 en 1753, 539.442 en 1787 y 726.665 en 1826 - y esto implicaba un número creciente de posibles confirmandos; sin embargo, es de reconocer que lo reducía la mortalidad infantiljuvenil $-37 / 38 \%$ en el siglo XVII, $33 / 35 \%$ en el XVIII y $28 / 30 \%$ en el XIX - a lo que en algunas zonas colaboraba la emigración desde edades muy precoces. Aun así, los números eran siempre impresionantes, revelasen un triunfo de la fe o más bien el poder del obispo. No es extraño, pues, que las cifras de confirmados entrasen a formar parte de la imagen de los prelados desde la biografía de Carlos Borromeo, que «administró el sacramento de la confirmación a un número casi infinito de personas» y que lo hacía «todos los días en las iglesias señaladas en cada región con sermón cada día del arzobispo... con largo y grave trabajo» ${ }^{15}$.También en las vidas de arzobispos compostelanos se esgrimen números espectaculares como prueba de su celo: Seixas y Losada habría confirmado en Salamanca a «más de sesenta mil personas» y fray Rafael Vélez a más de medio millón (Rodríguez, 1946: vol. 1, 224).

Para observar la realidad, empleamos 859 listas de confirmados desde la primera conservada, de 1591 a 1833, correspondientes a 519 parroquias, el 48,6\% de las 1069 que componen la diócesis y el 67,7\% cuyo registros están en el archivo diocesano compostelano ${ }^{16}$. Dado lo tardío de los archivos parroquiales gallegos, solo 101 listas son de 1591 a 1715, 404 de 1715 a 1800 y 354 del primer tercio del XIX. Por otra parte, el descuido en la aplicación del sacramento se refleja en la deficiente conservación de los listados, que los curas debían incluir en los libros de bautismos pero los hay en los de casados, de fábrica y de difuntos, y solo en algunas parroquias urbanas hubo libros específicos, a diferencia de Valladolid ${ }^{17}$, pero igual que en Cartagena (García e Irigoyen, 2006: 296). Cuanto más antiguas, las listas son más descuidadas, y esas y las posteriores carecen de un formato común. Con el tiempo, los curas anotaron los nombres y apellidos de los confirmados, el estado civil si eran adultos y su filiación cuando eran menores, sin dar edades. A veces se advierte

15. Luis Muñoz, Vida..., pp. 80 y 480.

16. Agradecemos a Damián Porto Rico y a Víctor Camino, del Archivo Diocesano de Santiago, el acceso a la base de datos y su ayuda al doctor Baudilio Barreiro Mallón.

17. En A Coruña los hay desde 1730 en la colegiata; en Santiago desde 1744. En Valladolid había libros en la capital en 1597 y en el resto de la diócesis, sobre todo en el XVIII (García, 2019: 53). 
OFELIA REY CASTELAO Y RUBÉN CASTRO REDONDO

EL SACRAMENTO OLVIDADO: LA CONFIRMACIÓN

EN LA ARCHIDIÓCESIS DE SANTIAGO, FINES DEL XVI A 1833

retraso en confeccionarlas si la ceremonia se celebraba en parroquia ajena, en cuyo caso los curas derivaban la responsabilidad a los padres de que los informasen de la confirmación de sus hijos ${ }^{18}$. Las listas no eran pura estadística: llama la atención la escasez de hijos naturales e ilegítimos, que aparecen de forma esporádica y tardía. Sí constan los expósitos que sus amos o tutores llevaban a confirmar, quizá por el control del Hospital Real de Santiago sobre esos niños entregados a familias particulares mediante pago de lactancia y crianza. En sentido opuesto, al comienzo de las listas solían anotarse los confirmados de más relieve social en la comunidad, cuando no fueron confirmados en privado.

El impulso pos-tridentino se inició con Francisco Blanco (1574-1581), defensor de las visitas pastorales en sus escritos - Suma de la doctrina cristiana, Advertencias a curas - y en su práctica, según sus biografías (Rey 2004: 13-102), pero no se conservan listas. Los dos mandatos siguientes fueron breves y aunque el de Juan de San Clemente en 1587 se inició con alguna confirmación - hay listas desde 1591-, el papa escribió en 1594 a Felipe II y a los obispos gallegos denunciando que «no ejercitaban la confirmación ni visitaban la diócesis» (Barreiro, 2002: 177-408). San Clemente respondió en su visita ad limina de 1595 argumentando que llevaba ocho años en la diócesis y que a pesar de visitar dos veces por año una parte de su territorio, no había podido completarla «por ser muy grande y constar de más de 1100 parroquias»; añadía la aspereza del terreno y las lluvias continuas, además de su edad provecta y las incursiones de los «herejes ingleses» (Rodríguez 1946: vol. 1, 108). No exageraba: la inseguridad de la costa fue real, por los ataques de Drake (1589) y los de piratas berberiscos a A Coruña y otras villas al menos hasta 1620-1630. La diócesis de Santiago ocupaba un territorio fracturado y montañoso, atravesado por dos ríos caudalosos cuyos puentes principales fueron destruidos por las riadas de fines del XVI y los caminos, muy malos, eran impracticables en los meses lluviosos y no mejoraron hasta fines del XVIII. Era una diócesis enorme, con 1060 parroquias en $8.549 \mathrm{~km}^{2}$, sin contar la vicaría de Alba y Aliste situada en Zamora, y la existencia de islas habitadas, que comportaban una mayor dificultad de acceso. Más del 95\% de las parroquias eran rurales, pequeñas (unos ocho $\mathrm{km}^{2}$ ) y de hábitat disperso. Los únicos núcleos urbanos importantes eran Santiago, Pontevedra y A Coruña, de corto tamaño los tres, pero cuyo crecimiento obligó a los prelados a prestarles cada vez más atención, al igual que a las villas de la costa.

En cuanto a la edad, San Clemente tenía entonces 61 años y sus sucesores también eran maduros - la mayoría murió en el cargo - al ser Santiago una diócesis de fin de carrera por su riqueza y poder, sin más posibilidades de ascenso que Sevilla y Toledo,

18. Por ejemplo, el cura de Aranga anotó en la lista de 1743 «no dejé de asentar alguno que a mi noticia viniere», y un sucesor suyo, que «son los que han dado razón que se habían confirmado», 30-10-1829 (AHDS, P 000958). 
OFELIA REY CASTELAO Y RUBÉN CASTRO REDONDO

EL SACRAMENTO OLVIDADO: LA CONFIRMACIÓN

EN LA ARCHIDIÓCESIS DE SANTIAGO, FINES DEL XVI A 1833

lo que influyó en la falta de celo pastoral. Solo hubo cuatro gallegos - Andrade, Gil Taboada, Rajoy y Malvar - y los demás llegaron de las Castillas, encontrándose una realidad muy diferente en Galicia. En muchos casos su estado físico les dificultó los viajes: fray Agustín Antolínez murió en Vilagarcía de Arousa en 1626 y Herrero y Esgueva en 1727 en Pontedeume, en sendas campañas de confirmación; fray José Villalobos estuvo siempre enfermo, Monroy en el largo final de su período, y la «cortedad de vista» disminuyó a Rajoy. La duración de los mandatos era breve -6,4 años en 1563-1602, 9,5 en el XVII, 10,6 después-, a lo que se unían los largos períodos de vacante y las frecuentes ausencias de los prelados para atender asuntos políticos o eclesiásticos o intereses de su cargo, si bien estos problemas se fueron paliando, en especial con los arzobispos posteriores al Concordato de 1753.

Fuera de la sede episcopal, las confirmaciones se hacían coincidir con visitas a la diócesis, pero estas fueron más numerosas que las confirmaciones por cuanto los arzobispos de Santiago, como muchos otros, recurrieron a visitadores (Castro, 2011: 255-268; Jaén 2011: 99-126). Para que estos pudieran confirmar, fue frecuente la designación de obispos auxiliares, como veremos, y que se aprovechase la presencia de obispos foráneos, a los que daban licencia ${ }^{19}$ : en Santiago en 1641 y 1820, los de Ourense Juan de Acevedo y Dámaso Iglesias; en A Coruña, en 1795, el de Puerto Rico, recién llegado de allí, y en 1796 Juan B. Bengotita, que hacía el viaje de ida a esa diócesis americana; en 1827, Sánchez Rangel, de Lugo; en 1833 el de Gran Canaria, Bernardo Martínez Carnero y en 1834 su sucesor, Judas José Romero; en 1810,en la villa de Mugardos, el obispo de Santander Méndez de Luarca, refugiado en el convento de Montefaro durante la irrupción de las tropas francesas. Sin embargo, no consta que hayan confirmado, al menos en el rural, los auxiliares de origen irlandés, Thomas Strong (1597-1601) y Nicholas French (1652-1666), quizá para evitar problemas de comunicación.

Siendo realistas, dado el efecto de la mortalidad hasta los siete o doce años edades canónicas de la confirmación-, lo más recomendable sería ir a confirmar mediando ese plazo para que se reuniera un número alto de candidatos. Pero esto no se cumplía y, salvo en períodos concretos, podían pasar muchos años entre dos confirmaciones. En cuanto a los recorridos de los arzobispos, al igual que las visitas, se organizaron a partir del mapa eclesiástico, potenciando el papel de los arciprestazgos. La lógica y la experiencia indicaban que lo más práctico era ir cada año en los meses mejores - de abril a octubre o noviembre, como hacía Lambertini en Bolonia - a un grupo de arciprestazgos limítrofes entre sí, fijando puntos de referencia en cada uno a los que se convocaba a los confirmandos de varias parroquias. Este método tenía la ventaja de que así funcionaba el sistema de información, de modo que acabó por actuar de forma casi automática. El 15\% de las parroquias eran anejas de otras

19. También en Valladolid (García, 2019: 51 y 55). 
OFELIA REY CASTELAO Y RUBÉN CASTRO REDONDO

EL SACRAMENTO OLVIDADO: LA CONFIRMACIÓN

EN LA ARCHIDIÓCESIS DE SANTIAGO, FINES DEL XVI A 1833

mayores y carecían de cura residente, lo que reducía el número de parroquias a visitar, al servir las matrices como anfitrionas ya que solían tener casas rectorales donde alojar al prelado y sus acompañantes. El alojamiento influyó en la selección de puntos de referencia: fuera de las ciudades, se eligieron villas, especialmente en la costa; lugares con conventos o monasterios - Herbón, Sobrado, Monfero-, o donde el arzobispo tenía su propia residencia - Lestrove, Pontevedra -, pazos de nobles titulados - marqués de Santa Cruz, conde de Ximonde, marquesas de Rubianes y Vilagarcía - y de hidalgos - pazos de A Buzaca Buzaca y de Anzobre - etc.

Más allá de las dificultades reales, actuó la voluntad de cada arzobispo para recorrer la diócesis, lo que remite a su sentido pastoral y a su orientación religiosa, pero también a su idea del poder episcopal y señorial y de hacerlos valer frente a otros poderes. Como veremos, no hubo en Santiago una pauta temporal como había en las diócesis más pequeñas y concentradas - Valladolid, una cada nueve años (García, 2019: 55) o Cartagena, una cada seis (García e Irigoyen, 2006: 297)—, aunque es imposible comprobarlo debido al método seguido en las visitas y a que no hubo dos mandatos iguales. La brevedad de algunos de estos no dio lugar a confirmaciones, o solo se iniciaron, por muerte, enfermedad o ascenso rápido de los prelados, circunstancias que se sumaron en la primera mitad del siglo XVII ${ }^{20}$, o en 1820-1825, en este caso por nombramientos frustrados. La falta de interés también es clara, más en el siglo XVII que en el XVIII: los dos Spínola, Agustín y Ambrosio, de 33 y 36 años, pasaron veloces por Compostela con la mirada puesta en Sevilla, y el gallego don Fernando de Andrade (1645-55) solo confirmó en sus primeros años, por estar entretenido en promocionar a su familia y en hacer política durante la guerra con Portugal. La edad y la salud pueden explicar que no confirmara Seixas y Losada, que se había distinguido por hacerlo en su diócesis anterior, Salamanca, pero Gil Taboada y de fray Sebastián Malvar, obispos muy visitadores en Lugo y Buenos Aires, fueron poco cumplidores en Santiago (Rodríguez Pazos, 1946: 224).

Juan de San Clemente (1587-1602) pasa por ser diligente en seguir los preceptos tridentinos y las visitas, pero las hacían sus visitadores, aunque en 1591 y 1593 estuvo en Salnés, en 1598 y 1601 en la villa de Noia, en 1599 en Cerveiro, todos en la costa, e incluso en la vicaría de Alba y Aliste en 1592 y 1594. Mayor impulso movió a su sucesor Maximiliano de Austria (1603-14)que confirmó en fechas diversas por sí mismo y con ayuda de su obispo auxiliar fray Francisco de Vera, yendo a la vicaría zamorana en 1612. De Pedro Carrillo (1655-1667) se conservan catorce listas que revelan su presencia en varios arciprestazgos. Bajo Andrés Girón (1670-81), un

20. Juan Beltrán de Guevara tuvo un mandato corto (1615-22), del que constan listas en A Coruña en 1616 e Iria en 1619. Sus sucesores no tuvieron tiempo para salir, y fray José González Villalobos (1627-1630) solo confirmó en Salnés en 1628. Igual que en Sevilla (Pérez, 2000: 205-233). 
OFELIA REY CASTELAO Y RUBÉN CASTRO REDONDO

EL SACRAMENTO OLVIDADO: LA CONFIRMACIÓN

EN LA ARCHIDIÓCESIS DE SANTIAGO, FINES DEL XVI A 1833

arzobispo rigorista, las visitas se hicieron metódicas pero orientadas al control del clero, por lo que el descontento de este y del cabildo catedralicio puede explicar que solo encontremos 26 listas de parroquias cercanas a la capital o en la costa y solo al inicio de su mandato. El dominico mexicano fray Antonio Monroy, que estuvo muchos años (1685-1715), aseguraba en su visita ad limina haber visitado toda la diócesis y atribuía sus dificultades al clima; lo cierto es que confirmó en sus primeros años, cerca de Santiago y en dos campañas en 1688-1689 y en 1693-1694; desde 1705 lo sustituyó su obispo auxiliar don José A. Jaspe Montenegro, que figura en numerosas listas, incluso en los años de la dura crisis pestífera de 1709-1710. Fechas y lugares pueden verse en el mapa número 1.

Los siguientes arzobispos llegaron a edades inferiores a los del siglo XVII y la mayoría murió en el cargo. Los períodos de gobierno, más largos y estables, y el nombramiento de obispos auxiliares facilitaron que las campañas de confirmación fueran más frecuentes. Los enormes problemas de Luis de Salcedo y Azcona con el cabildo catedralicio explican que hasta su ascenso a Sevilla en 1722 estuviera recorriendo la diócesis, incluso en años santos, yendo cada año a un grupo de arciprestazgos; de hecho, aprovechó la larga espera para entrar en Santiago que lo retuvo en el monasterio de Sobrado, para confirmar allí y en otros pueblos en su viaje hacia la sede, y al poco de llegar, en 1716, estuvo en A Coruña, como hicieron algunos de sus antecesores y harán todos los que le siguieron. Esas tácticas fueron calcadas por Miguel Herrero y Esgueva, quien daba una gran importancia a las visitas pastorales y distribuyó su acción entre 1724 y 1725, ampliando el número de arciprestazgos y de parroquias, ayudado en 1727 por su auxiliar Pose de Soto. Su interés en hacer un sínodo y en imponer el poder episcopal lo enfrentaron con el clero de la diócesis y en especial con el cabildo, de ahí que «huyera» de Compostela; de hecho, murió en plena campaña de confirmación. Los conflictos se agudizaron con José del Yermo Santibáñez (1728-37) al convocar este el sínodo en 1735, y visitó poco territorio - hay listas en treinta parroquias - aun teniendo un auxiliar desde 1732 (Barreiro, 2002: 282 y 289). El sínodo, que se frustró, era solo parte de una lucha de poder, de modo que los recorridos de Salcedo y de Herrrero confirmando a cientos de fieles eran una demostración del suyo propio, tanto en lo eclesiástico como en lo señorial. Quizá por eso de tiempos de Manuel Orozco Martínez de Lara (1738-1745) se conservan 94 listas, sobre todo al entorno de A Coruña y de zonas del litoral, firmadas por sus auxiliares Zapata Sandoval y Lorenzo Taranco Mujaurrieta. Como ya dijimos, la actividad de Gil Taboada fue menor - hay treinta listas de catorce arciprestazgos -, quizá por enfrascarse en reunir, publicar e imponer el sínodo por el que sus antecesores habían luchado.

Los arzobispos de la segunda mitad del XVIII, en especial los posteriores al Concordato de 1753, tampoco tuvieron un comportamiento homogéneo. Rajoy y Losada se aplicó a una intensa actividad asistencial, antes y después de la terrible 
OFELIA REY CASTELAO Y RUBÉN CASTRO REDONDO

EL SACRAMENTO OLVIDADO: LA CONFIRMACIÓN

EN LA ARCHIDIÓCESIS DE SANTIAGO, FINES DEL XVI A 1833

crisis de 1769-1770 que arrasó la diócesis, y a mejorar la formación del clero, de modo que inició su mandato con cierto ímpetu - hace confirmaciones en 1753, 1754, 1755 y $1756-$, pero sus problemas de vista le hicieron delegar en el auxiliar Juan Varela Fondevila. Su sucesor no podría ser más diferente: el andaluz Francisco Bocanegra entró en Compostela en 14-8-1773 en medio de un grave conflicto de protocolo con el cabildo y los regidores de la ciudad. En su anterior destino, Guadix, había desplegado una intensa labor misional y en Santiago se implicó mucho en las confirmaciones, de modo que en diez años (1773-1783) contamos con 74 listas por toda la diócesis, si bien prestó una especial atención a A Coruña, ciudad convertida en el epicentro comercial de Galicia y en un lugar donde iban cuajando ideas nuevas que no agradaban al arzobispo. Este prelado apoyó sus campañas de confirmación en cartas pastorales - en especial la de 1778-, en predicaciones - él era un gran orador y además, hizo que los capuchinos de Salamanca recorrieran la diócesis - y en fortalecer el ritual imponiendo la presencia de padrinos y madrinas, implicando así a personas destacadas de la sociedad urbana y rural. Los mandatos siguientes no mantuvieron el mismo ritmo: el franciscano gallego Malvar y Pinto, procedente de Argentina, tardó en incorporarse - llegó a fines de 1784- y apenas dedicó esfuerzo a confirmar - veinte listas en once años-, aunque mantuvo la táctica de la predicación asociada a la confirmación - por ejemplo, recurrió a fray José de Cádiz para misionar en Santiago y A Coruña ${ }^{21}$-; en cuanto a Fernández Vallejo estuvo apenas tres años (López, 1911: 11-85).

Bocanegra y sus sucesores tuvieron que afrontar un período ideológicamente inquieto, lo que afectó incluso a miembros del cabildo catedralicio y de la Universidad en Santiago, y sobre todo a los comerciantes ricos de A Coruña, ante lo cual los prelados desplegaron una actividad más política que pastoral, aunque aprovecharon todos los resortes de esta dimensión y su elevada condición eclesiástica en función de la política. No debe olvidarse que el pueblo era cada vez más reacio a pagar las rentas de las que vivían los arzobispos - en especial el Voto de Santiago y los diezmos - y que su poder señorial pasaba por problemas tanto en la ciudad de Santiago como en el territorio del señorío; abolidos esos privilegios por las Cortes de Cádiz en 1812, su restauración posterior se hizo en precario y ya nada era igual. En ese contexto, los recorridos por toda la diócesis confirmando y dando cada vez más boato al ritual, permitían reunir a mucha gente, tanto en las ciudades y villas como en el campo, y así hacer una demostración de poder.

Quizá el arzobispo navarro Rafael Múzquiz (1801-1821) hubiera explotado más esa vía si su gobierno no se viese alterado por la invasión francesa en 1809, los subsiguientes sucesos políticos y militares, sus conflictos con el clero compostelano y su implicación en las luchas entre conservadores y liberales, en las que

21. Archivo Histórico Municipal de A Coruña, Libro de Acuerdos, 1/1/1795. 
OFELIA REY CASTELAO Y RUBÉN CASTRO REDONDO

EL SACRAMENTO OLVIDADO: LA CONFIRMACIÓN

EN LA ARCHIDIÓCESIS DE SANTIAGO, FINES DEL XVI A 1833

extremó su absolutismo político (Vázquez, 2004: 191-197; García, 1982: 355-387). Múzquiz tardó dos años en llegar a Santiago (24-9-1803) y lo hizo sin experiencia pastoral, ausentándose muchas veces - se va Madrid en 1804 por un año, durante la invasión se refugió en Ayamonte y luego huyó a Portugal-. En lo que nos atañe, visitó y confirmó en casi todos los arciprestazgos entre 1805 y 1808, pero luego le fue imposible, y solo hay listas ocasionales en 1820. Desde la muerte de Múzquiz en mayo de 1821 a marzo de 1825 Santiago estuvo sin prelado y, por lo tanto, sin confirmaciones (mapa 2, 1715-1820).

El del capuchino Fray Rafael Vélez fue también un período convulso, el posterior al Trienio Liberal, con sus purgas políticas, muy duras en A Coruña. Tenía 47 años y era un militante antiliberal, destacado por sus beligerantes publicaciones en defensa del absolutismo y de apología del altar y el trono, a lo que quizá debía la rapidez de su carrera (Vázquez, 2004: 106 y 2015; Barreiro, 1982). En Santiago dio una enorme importancia a las visitas pastorales y a la confirmación, claves en su estrategia de ejemplo para los párrocos y adoctrinamiento de los fieles, lo que acompañaba de conferencias morales y misiones de frailes capuchinos. Quizá por eso, ya antes de llegar a Santiago nombró obispo auxiliar a fray Manuel María de Sanlúcar, compañero de orden, de edad y de ideología. El método de las visitas estaba ya definido, pero Vélez lo perfeccionó desplegando una parafernalia pública cargada de intención política. Así pues, tenemos listas de 301 parroquias - mapa 3-, reflejo de un programa bien establecido, yendo cada año a dos o tres arciprestazgos próximos entre sí, lo que incluyó la vicaría de Alba y Aliste en 1832. En sus visitas ostentaba gestos de caridad, como el reparto de mantas y ropas entre los pobres, pero era amante del boato, por lo que anunciaba su llegada con suficiente antelación para que las autoridades locales preparasen su recibimiento. Por ejemplo, el 18-101825, el gobernador presidente del municipio de A Coruña recibió la notificación de que entraba en la ciudad, enviando sus respetos a los concejales; reunidos estos, dispusieron que dos de ellos acudirían a recibirlo - con dos porteros y un clarín - y a cumplimentarlo al día siguiente, que se emitiesen bandos para que los coruñeses iluminasen y engalanasen sus casas «con el decoro y aseo posible, como lo espera el Ayuntamiento de su religiosidad», a pesar de que muchos concejales eran hombres de negocios con escaso entusiasmo absolutista y poco sentido piadoso ${ }^{22}$. Mucho

22. «La ciudad en su vista, deseosa de manifestar la satisfacción y júbilo que le cabe en la venida de tan digno y benemérito prelado: acordó salgan a su recibimiento a la puerta de la Torre dos señores capitulares con sus Porteros y clarín según costumbre, los quales el día de mañana pasen a felicitar a S.E. en nombre de la misma y que por separado se pongan los bandos y pasen los oficios de costumbre imbitando a todos los vecinos de este pueblo para que se sirvan iluminar las casas desde las ocho hasta las once de la noche y los de la Carrera por donde pase S.E. colgar sus frentes con el decoro y aseo posible, como lo espera el Ayuntamiento de su religiosidad», Libro de acuerdos,18-10-1825. 
OFELIA REY CASTELAO Y RUBÉN CASTRO REDONDO

EL SACRAMENTO OLVIDADO: LA CONFIRMACIÓN

EN LA ARCHIDIÓCESIS DE SANTIAGO, FINES DEL XVI A 1833

más llamativo fue el recibimiento en el puerto de Muros en 7-2-1826: llegado Vélez por mar, dos miembros del cabildo de la colegiata fueron a recibirlo en una gran falúa; 24 muchachos marineros «perfectamente vestidos que remaban con mucho aire y orden; llevaban la bandera española en el sitio en el que le pertenece, como a Teniente General»; en otras dos lanchas empavesadas iban los regidores y muchos particulares, y los barcos extranjeros se adornaron al efecto; en tierra, la comitiva fue acompañada por el regimiento militar de Santiago, recorriendo la adornada villa en medio de fusilazos, cañonazos y cohetería, mientras el prelado utilizaba la magnífica carroza que los canónigos le habían preparado (Couselo, 1927: 108). Sin embargo, al inicio de la guerra carlista, en 1833 Vélez y su auxiliar fueron juzgados y, en 1835, desterrados, aunque las autoridades de A Coruña se aseguraron la confirmación de sus hijos gracias a la presencia Judas Romero, obispo de Canarias.

\section{LA PRÁCTICA EN SU REALIDAD: REPRESENTACIÓN DEL PODER Y ADOCTRINAMIENTO}

En todo lo referente a este capítulo es clave lo que dicen las instrucciones de 1732 del papa Lambertini dejadas a sus sucesores y al clero de Bolonia. Lambertini declaraba que en solo quince meses había salido cinco veces «hasta los lugares más distantes, pero siendo grande y vasta nuestra diócesis y estando situada gran parte de ella en remotas y ásperas montañas y otras partes en la llanura y en medio de las aguas», había decidido que la visita empezase en la ciudad en noviembre hasta la primavera, para visitar luego el resto del territorio. El obispo anunciaba al cura su visita quince días antes y la hacía en día de fiesta de precepto para explicar la doctrina, si no «sería muy difícil juntar los niños y las niñas en los días de trabajo o feriales». La ceremonia se abría con una misa y se confirmaba «solo a los de aquella parroquia», para que «se logre nuestro intento que es evitar la confirmación inseparable compañera de la multitud». El obispo se pagaría los gastos. Lambertini subraya que lo mejor era confirmar al ir en visita pastoral, pero esto dificultaba hacerlo en Pascua y Pentecostés, por lo que había quedado al arbitrio de los obispos. Antes de confirmar, había que hacer una breve disposición de voz, pero, dado el gran número de parroquias de la diócesis, era una «enfadosa fatiga»; así pues, ordenaba que los curas supieran lo que afectaba a los confirmandos, esto es, que estuviesen «en los años de la discreción», no antes de los siete, salvo peligro de muerte, y separados hombres de mujeres en el templo, en el que estarían también los padrinos, unos y otros con compostura exterior. Todo lo demás se refiere al ritual de la bofetada que el obispo debía dar al confirmando, la imposición de una mezcla de óleo y bálsamo y la de una venda en la frente que se llevaría durante un día ${ }^{23}$.

23. Próspero Lambertini, Instrucciones..., 26-27. 


\section{OFELIA REY CASTELAO Y RUBÉN CASTRO REDONDO \\ EL SACRAMENTO OLVIDADO: LA CONFIRMACIÓN \\ EN LA ARCHIDIÓCESIS DE SANTIAGO, FINES DEL XVI A 1833}

Buena parte de estas instrucciones es recogida en las de Bocanegra de 1774, muy prolijas en la organización del ceremonial, indicando a los curas que anunciasen el día con tiempo «al pueblo, llamándolo con señal de campana», de modo que los adultos se dispusieran a recibir la confirmación y que padres y madres llevasen a los párvulos. El párroco los instruiría en el silencio, la modestia y la compostura en el templo. Los confirmandos tenían que llevar «una venda de lienzo, u de otra cosa decente, i limpia»; los sacerdotes tendrían que ponérselas, además de lavarlas después y quemarlas en el baptisterio para no profanar el crisma y que «no sirvan en profanos usos». Por supuesto, la iglesia estaría desembarazada de bancos para no «estorvar el buen orden en entrar i salir las personas».

Decía el papa Lambertini que la confirmación era «inseparable compañera de la multitud», por lo que prefería repetir las ceremonias y reunir a pocos confirmandos, pero reconocía que esto solo podía hacerlo en la ciudad. Los arzobispos de Santiago optaron por una fórmula u otra según fuera más útil a sus intereses y circunstancias y a los de los lugares de confirmación. Es fácil comprender que la aparición de los arzobispos con parte de su corte y en medio del boato que les permitían los viajes, era algo infrecuente y extraordinario (García 2019: 58; Béthencourt, 1999), y eso mismo podía dar pie a la concurrencia de los fieles para ver y la de los poderosos locales para hacerse ver, en especial cuando se implicó a estos en el apadrinamiento de los confirmandos y cuando el ritual se hizo más cuidado, por lo que la fórmula multitudinaria fue la preferida. Veamos los resultados.

La atención prioritaria de los arzobispos se concedió a las ciudades. La táctica de celebrar muchos actos de confirmación en días diferentes en diferentes templos a los que acudían los confirmandos de la ciudad y de parroquias vecinas, incluidos los hospicianos, hacía que las ceremonias fueran socialmente transversales y muy valiosas para hacer visibles a los arzobispos y a los otros participantes, en especial los padrinos. Santiago era la sede de la diócesis y hubo confirmaciones al menos cada diez años para atender a una población que tenía 6589 habitantes en 1607, 14862 en 1708, 16807 en 1753, 17400 en 1800 y 22744 en 1849 . Como en las otras ciudades, encontramos dos modelos de ceremonia, el multitudinario y el reducido. Por ejemplo, en la parroquia de Santa María del Camino, el arzobispo Salcedo confirmó en 3-4-1720 a 130 y a 40 en San Benito; Orozco en 2-5-1732 a 50 y su auxiliar Taranco en 4-2-1742 a 140; a 110 Gil Taboada en 9-11-1746; y el auxiliar Fondevila en 29-4-1777 a 240; 750 Malvar en 20-3-1787; Fernández Vallejo en el palacio arzobispal en 19-2-1799 a 250 y a 135. Vélez confirmó en 17-2-1825 en la capilla de Ánimas a 105 y 224 el 11 de julio en el colegio de la Compañía de María. La capilla arzobispal también fue utilizada por Múzquiz el 8-3-1810 para confirmar a los cuatro hijos de don Domingo Ramón González y el 13-4-1812 a varias familias del común; el monasterio de Pinario fue el lugar en 18-12-1812 para solo cinco y 
OFELIA REY CASTELAO Y RUBÉN CASTRO REDONDO

EL SACRAMENTO OLVIDADO: LA CONFIRMACIÓN

EN LA ARCHIDIÓCESIS DE SANTIAGO, FINES DEL XVI A 1833

en 19-9 a 180 apadrinados por el conde de Maceda y la condesa de Ribadavia, y ese mismo día y los dos siguientes confirmó a 160 en Santa María, etc. ${ }^{24}$.

Lo mismo hicieron los arzobispos en A Coruña, ciudad de realengo y residencia del Gobernador y de la Real Audiencia, que solían visitar al comienzo de sus mandatos. La población coruñesa pasó de 6069 habitantes en 1600 a 8360 en 1753, 13575 en 1787 y 27359 en 1851, pero, además, el interés por ese puerto creció desde que la Corona instauró allí los Correos Marítimos con América (1764) y se convirtió en polo económico de Galicia, a lo que se unió la necesidad de neutralizar el progresivo desafecto ideológico y político de los sectores mercantiles con respecto al clero compostelano. Así pues, los prelados dedicaron esfuerzos a $\mathrm{A}$ Coruña, repitiendo ceremonias en la colegiata, en las parroquias y en los conventos o enviando a sus auxiliares. En 1616 acudió el obispo Vera; en 1626 se confirmaron 188 en la parroquia de Santiago y 295 en San Nicolás; en 1659 estuvo el arzobispo Carrillo, en 1672 Girón; en 1707 el auxiliar Jaspe, que confirmó a 406 en San Jorge; en esta parroquia estuvo Salcedo en 1722 (354 confirmados); en 1730 Yermo; el obispo Fondevila atendió a 1653 en 1772 - el 10\% de la población - y Bocanegra en varios días de 1774 a 1316 y a 713 en 1779; en 1791 solo en la parroquia de San Jorge había por confirmar unos 3600 y en 1795 y 1796, los obispos de Puerto Rico bendijeron a 685 y 170; 377 Fernández Vallejo en 1798 y 960 Múzquiz en 1810, pasando luego años sin visita por la situación bélica y política ${ }^{25}$.

Todo lo cual no evitó que en 17-10-1820, a comienzos del Trienio, el ayuntamiento liberal de A Coruña permitiese al concejal Suárez de Pazos defender que se «representase al Congreso solicitando el establecimiento de una silla episcopal en esta ciudad», convirtiendo la colegiata en catedral, aportando argumentos «en demostración de la importancia de este pensamiento considerado moral y políticamente»: votaron a favor ocho de diez concejales, comerciantes que habían costeado el levantamiento progresista de aquel año y que pertenecían a clubes masónicos o de opinión bastante radicales, lo que resulta un tanto paradójico (Mariño, 2009: 80 y 87). La propuesta emulaba la creación de la diócesis de Santander y no pasó a más, pero influyó en que fray Rafael Vélez o su auxiliar residiesen allí en estancias de otoño a febrero prodigándose y marcando territorio, en ceremonias con numerosos confirmandos y con padrinos relevantes. Trataban también de neutralizar los enfrentamientos entre el cabildo de la colegiata y el municipal por cuestiones fiscales, el despliegue de fiestas civiles y políticas fomentadas por el ayuntamiento, e incluso la reacción de este contra el traslado de la Capitanía General de Galicia a

24. AHDS, P019960, P19961, P19962 y P19963.

25. AHDS, P009051, P009082 a P09085; P008866, P008870, P008871, P0008877, P009338, P09339, P009365. 


\section{OFELIA REY CASTELAO Y RUBÉN CASTRO REDONDO \\ EL SACRAMENTO OLVIDADO: LA CONFIRMACIÓN \\ EN LA ARCHIDIÓCESIS DE SANTIAGO, FINES DEL XVI A 1833}

Santiago en 1824, obra del Gobernador Nazario Eguía, conservador radical y aliado de Vélez (Barreiro, 1986: 418).

Para atender al resto de la enorme diócesis, los arzobispos empleaban los meses de primavera a inicios de otoño, yendo, como hemos dicho, a lugares de referencia, lo que fue fácil en el entorno de las ciudades. Por ejemplo, entre los confirmados por Orozco en 1732 y en 1799 por Vallejo en el palacio arzobispal, muchos eran del rural cercano a Compostela. Más claro es todavía en A Coruña: en 1810 Múzquiz confirmó en el convento Santa Bárbara a los procedentes de O Burgo, Elviña, Vilamaior, Visma, Nos, Iñás, Pravío, Oza, etc., en un radio de unos diez kilómetros. Según datos de Pablo Nogueira, en 1774 la cifra había llegado a 5.934; en 1779 a 2463 y 7450 en 1796 debido a esa práctica (Nogueira, 2003: 261)26. Igual de útil fue la red de pequeñas villas, convertidas en puntos logísticos para alojar a los prelados y para las visitas y confirmaciones. Así, por ejemplo, Múzquiz convocó en Noia a varias parroquias cercanas en octubre-noviembre de 1807, acudiendo, entre otros, 129 de Entíns; Vélez en Corcubión en 10-5-1827 confirmó a 157 personas y el 11 a 113, actuando como padrinos don Manuel Domínguez y doña Petra Castril, esposa de don Félix Delgado, vecinos de la villa, y en Carril en noviembre de 1827, a 552, la mayoría foráneos ${ }^{27}$.

A falta de villas, los arzobispos se detenían en parroquias grandes del rural. Por ejemplo, del 13 al 20 de junio de 1828 Vélez confirmó en la iglesia parroquial de Armentón y en la capilla del pazo de Anzobre a varios centenares, apadrinados por don Jacinto Filipez y doña Josefa Caamaño, de la hidalguía local, y del 24 al 29 de mayo de 1829 en Saiáns, hasta sumar cerca de tres mil confirmados, también apadrinados por parejas de notables; en octubre estaba muy lejos, en el monasterio de Monfero, donde confirmó a 320, etc. La variación en los puntos elegidos por cada arzobispo podía hacer que los de una parroquia cambiasen de lugar en cada ocasión: por ejemplo 56 de Espenuca fueron en 1743 a Coirós; 68 a Ois en 1770; 99 a Betanzos en 1828; y los de Rutis en 1721 y 1742a Elviña, Iñás, etc. ${ }^{28}$ La ventaja para los prelados estaba en que, al reunir dos o más parroquias, ganaban en espectacularidad litúrgica y economizaban esfuerzos ${ }^{29}$.

Las islas y los territorios zamoranos presentaban especiales dificultades operativas. La isla de Arousa tenía 362 habitantes en 1753 y si bien la distancia al continente no es mucha, las corrientes limitan el acceso al sur o al este. Algunas veces los arzobispos se atrevieron a ir en barco: Salcedo en enero de 1717 confirmó a 238

26. En Cartagena era lo mismo (García e Irigoyen, 2006: 297).

27. AHDS, P10967, P11131.

28. AHDS, P011038, P011039.

29. Por ejemplo, en Fuerteventura en 1792 se confirmaron tres mil, 26,5\% de la población (Béthencourt, 1999: 281). 
OFELIA REY CASTELAO Y RUBÉN CASTRO REDONDO

EL SACRAMENTO OLVIDADO: LA CONFIRMACIÓN

EN LA ARCHIDIÓCESIS DE SANTIAGO, FINES DEL XVI A 1833

personas apadrinadas por don Cristóbal Jiménez, su tesorero personal, y 38 por don Juan de Briones, clérigo de Caleiro, y en 1725 acudió el arzobispo Herrero. Pero en las demás ocasiones los confirmandos fueron llevados a los puertos de tierra firme, lo que suponía una operación bastante compleja: en 1676 Girón confirmó en Vilamaior; Monroy en 1688 y Zapata en 1740 en Vilanova de Arousa; Bocanegra en Cambados en 1776, etc. ${ }^{30}$ Con respecto a la vicaría zamorana de Alba y Aliste, tenía 48 parroquias matrices y 83 pueblos, y unos 3500 vecinos tanto a comienzos del XVII como al inicio del XIX; los prelados solían visitarlos aprovechando sus viajes fuera de Galicia e incluso iban adrede, como don Maximiliano de Austria, que hizo allí un sínodo en 1612 para dejar claro su poder frente al obispo de Zamora; también estuvieron San Clemente en 1592-93, Girón en 1670 o Vélez en $1832^{31}$.

El traslado de los confirmandos dejaba a los párrocos la responsabilidad de controlar que sus feligreses acudieran a parroquias ajenas, mientras que los curas de estas se desentendían: así lo reflejó el de San Jorge de A Coruña, al anotar que parte de los novecientos confirmados en abril de 1810 "lo son de otras que se fueron antes de decir de dónde ${ }^{32}$. Lo cierto es que los párrocos no siempre los acompañaban y que eso facilitaba el incumplimiento por parte de los fieles. Ya en 1973 Baudilio Barreiro llamó la atención sobre ese hecho, de modo que, por ejemplo, en 1728 se confirmaron en Arantón (Xallas) 358 personas - hacía tiempo de la última-, pero en 1736 el arzobispo los convocó en a Santa Comba y solo fueron veinte, cuando entre esas dos fechas habían nacido 180 y había 113 supervivientes. Hemos comprobado lo mismo en 1676 cuando el arzobispo Girón concentró las confirmaciones en la villa de Caldas de Reis y solo se presentaron seis de Campo Lameiro, mientras que lo hicieron 225 cuando Monroy confirmó in situ ${ }^{33}$.

Pero las ausencias también se comprueban sin que hubiera traslado. En el arciprestazgo de Salnés, mediante reconstrucción de familias, José M. Pérez García observó que, además de haber muerto un $31 / 32 \%$ de los nacidos, en las listas faltaban familias enteras, a pesar de que las visitas eran frecuentes $-1718,1725$, 1739, 1749... - (Pérez, 1979: 17), e Hilario Rodríguez Ferreiro en Morrazo, por la misma vía, constató que entre 1676 y 1688 muchos que estaban en edad hacerlo, no se presentaron o estaban ausentes (Rodríguez, 2004: 56). En el valle del Ulla, cercano a Santiago, hemos calculado las bajas entre dos confirmaciones, por muerte o por ausencia:

30. AHDS, P012020, P012021 y P010022.

31. Residían 3513 vecinos a comienzos del XVII, 3040 en 1753, 3452 en 1791 y 3461 en 1829. Los arzobispos tuvieron conflictos con los obispos de Zamora por su control (Barreiro, 2002: 320).

32. AHDS P08877, s.f.

33. AHDS P06002. 
OFELIA REY CASTELAO Y RUBÉN CASTRO REDONDO

EL SACRAMENTO OLVIDADO: LA CONFIRMACIÓN

EN LA ARCHIDIÓCESIS DE SANTIAGO, FINES DEL XVI A 1833

Tabla 1. Confirmados en parroquias de A Ulla

\begin{tabular}{|c|c|c|c|c|c|c|c|c|}
\hline & $\begin{array}{c}\text { CoNfIRMACIÓN } \\
\text { ANTERIOR }\end{array}$ & $\begin{array}{c}\text { CONFIRMACIÓN } \\
\text { CONTROLADA }\end{array}$ & $\begin{array}{c}\text { NIÑOS } \\
\text { NACIDOS }\end{array}$ & $\begin{array}{c}\text { NIÑAS } \\
\text { NACIDAS }\end{array}$ & $\begin{array}{c}\text { CONFIR- } \\
\text { MADOS }\end{array}$ & $\begin{array}{c}\text { CONFIR- } \\
\text { MADAS }\end{array}$ & $\begin{array}{c}\text { DESAPA- } \\
\text { RECIDOS }\end{array}$ & $\%$ \\
\hline Vilanova & 1607 & 1613 & 21 & 12 & 7 & 10 & 16 & 46,4 \\
\hline & 1737 & 1748 & 59 & 70 & 38 & 52 & 39 & 30,2 \\
\hline & 1777 & 1786 & 50 & 60 & 38 & 50 & 22 & 20,0 \\
\hline Ribadulla & 1737 & 1748 & 126 & 119 & 65 & 91 & 89 & 36,3 \\
\hline & 1777 & 1786 & 89 & 86 & 56 & 48 & 71 & 40,5 \\
\hline & 1831 & 1845 & 113 & 134 & 65 & 85 & 97 & 39,2 \\
\hline Ribeira & 1718 & 1724 & 46 & 50 & 30 & 36 & 30 & 31,2 \\
\hline & 1780 & 1786 & 48 & 39 & 28 & 26 & 33 & 37,9 \\
\hline
\end{tabular}

Fuente: Rey Castelao, 1981: 271.

Debe tenerse en cuenta que las confirmaciones se hacían en primavera y verano, en pleno auge del calendario laboral. Además, en estas comarcas muchos hombres y adolescentes emigraban durante meses e incluso años a Castilla, Andalucía y Portugal, lo que ayuda a explicar las ausencias; otro dato revelador es que en casi todos los listados de confirmados predominan ampliamente las mujeres, lo que no excluye que muchas de estas también estuvieran fuera, empleadas como criadas o participando en las siegas de Castilla.

El absentismo no era un problema exclusivo de Galicia: baste recordar lo que decía Lambertini con respecto a Bolonia. En Santiago, la instrucción de Bocanegra de 1774 recordaba a los padres y madres de familia,

que en el día señalado no envíen fuera los bijos, criados o personas que están a su cargo, porque no pierdan la ocasión de ser confirmados; i se les pondere el grande mal que en esto hacen a las Almas, defraudándolas de tanto bien; porque se experimenta (ino sin grave dolor) que muchas personas habitantes en Pueblos, a donde no ha entrado Obispo por muchos años, sabiendo el día determinado en que viene, se van ese mismo día a sus labores, i obras temporales, ise quedan sin confirmar; lo qual sin duda es una grande negligencia, $i$ culpable desidia en orden a las cosas espirituales o es contingente, que en castigo de esta poca estimación i aprecio de cosa tan sagrada, les deje Dios caer en algunas culpas, de que fueran preservados si recibieran el Sacramento.

Quizá la prolongada incomparecencia de los arzobispos sin que la falta de confirmación tuviera consecuencias en los feligreses relajaría posibles temores de estos, a lo que colaboraba la desidia del clero parroquial. En ausencia de listas, los períodos largos sin confirmaciones se detectan, en primer lugar, en las cifras acumuladas. En 1688 Monroy confirmó a 225 en Campo Lameiro y Salcedo a 140 en 1718; Salcedo a 380 en 17-4-1720 en Entíns y Taranco a 102 en 22-8-1740; en 1727 Yermo a 220 en Aranga, 290 en 1743 Taranco y 340 Fondevila en 1772; en Arantón en 1720 fueron 358 y 572 en Santa Sabina y 206 en 1741; 290 en Saiáns, en 1829 en Caamouco 212 
OFELIA REY CASTELAO Y RUBÉN CASTRO REDONDO

EL SACRAMENTO OLVIDADO: LA CONFIRMACIÓN

EN LA ARCHIDIÓCESIS DE SANTIAGO, FINES DEL XVI A 1833

por Vélez ${ }^{34}$, etc. Se trata de parroquias de entre cuatrocientos y seiscientos habitantes, por lo que a veces se confirmó a más de la mitad de la población.

Otro indicador, mucho más expresivo, es el hecho de que los arzobispos confirmasen sin mirar la edad ni la condición de los candidatos, es decir, lo hacían de forma "preventiva», por cuanto no se sabía cuándo sería la siguiente ocasión. Esto excluye que su celebración actuase como un rito de paso - se confirmaban niños de pecho tanto como ancianos-, como sí podía serlo la primera comunión, que se recibía en torno a los siete años (Mellot 1987: 171-196). No era algo exclusivo de Santiago: el arzobispo Martini de Florencia en sus instrucciones de 1785 justificaba la «premura que siempre hemos tenido de administrar la crisma a los niños, aun de tierna edad» debido a «los accidentes» ${ }^{35}$. Así pues, los arzobispos aceptaban una situación de hecho - en este caso, la mortalidad infantil-y confirmaban a niños y niñas de brazo; conviene tener en cuenta, además, que, siendo siete años la edad mínima, todavía el código de derecho canónico de 1932 reconocía que «en España puede conservarse la costumbre de administrarlo antes de esa edad» ${ }^{36}$.

Dado que las listas no dan edades, Rodríguez Ferreiro pudo comprobarlo utilizando las actas de bautismo de Hío (Morrazo): el 40,8\% de los nacidos habían muerto antes de la confirmación de 5-6-1676 y los 181 que figuran en la lista tenían estas edades:

Tabla 2. Edad de los confirmados en Hío (Morrazo)

\begin{tabular}{|c|c|}
\hline AÑOS & CASOS \\
\hline 0 & 19 \\
\hline 1 & 14 \\
\hline 2 & 24 \\
\hline 3 & 18 \\
\hline 4 & 15 \\
\hline 5 & 14 \\
\hline 6 & 9 \\
\hline 7 & 13 \\
\hline 8 & 12 \\
\hline $9 \mathrm{y} 10$ & 16 \\
\hline $11 \mathrm{a} 17$ & 17 \\
\hline
\end{tabular}

Fuente: Rodríguez Ferreiro, 2004: 56.

34. AHDS, P10965, P10966, P00537.

35. Antonio Martini, Instrucciones..., p. 35.

36. Código de derecho canónico, BAC, Madrid, 1945, p. 788. 
OFELIA REY CASTELAO Y RUBÉN CASTRO REDONDO

EL SACRAMENTO OLVIDADO: LA CONFIRMACIÓN

EN LA ARCHIDIÓCESIS DE SANTIAGO, FINES DEL XVI A 1833

Sin necesidad de hacer tanto esfuerzo, es un indicio suficiente del retraso y de la confirmación indiscriminada la presencia en las listas de adultos, personas casadas, grupos de hermanos y familias enteras. Veámoslo en dos parroquias de la comarca de A Ulla, visitada con cierta frecuencia por los arzobispos dadas su proximidad a Compostela y la concentración de pazos o residencias de nobles e hidalgos. En San Pedro de Vilanova - feligresía con 361 habitantes en 1753-, Maximiliano de Austria y su auxiliar confirmaron en 1607 a 47 hombres y 46 mujeres de los que 29 eran hijos únicos, 11 dos hermanos, 6 tres y uno cuatro; en 1724 fueron 29, de los que once eran hijos únicos, 4 dos, 3 tres, sin adultos; en 1735 fueron 75, pero en 1777 se confirmaron familias enteras al igual que en $1831-104$ eran hijos únicos pero los demás eran grupos de hermanos muy numerosos $-{ }^{37}$.

En otra parroquia, Foxás, que tenía 473 habitantes en 1753, hemos podido calcular los confirmados por grupos familiares desde 1607 a 1831, comprobando, de nuevo, el elevado número de hijos confirmados por unidad familiar cuando el retraso era importante:

Tabla 3. Número de hijos confirmados por grupo familiar en Foxás

\begin{tabular}{|c|c|c|c|c|c|}
\hline $\begin{array}{c}\text { HIJOS } \\
\text { POR NÚCLEO }\end{array}$ & 1607 & 1737 & 1748 & 1774 & 1831 \\
\hline 1 & 13 & 45 & 38 & 31 & 45 \\
\hline 2 & 19 & 17 & 13 & 24 & 29 \\
\hline 3 & 9 & 8 & 4 & 15 & 27 \\
\hline 4 & 7 & 5 & 1 & 2 & 11 \\
\hline 5 & 1 & 2 & - & - & 4 \\
\hline 6 y más & - & 1 & - & 4 & 6 \\
\hline Total & 49 & 78 & 56 & 76 & 122 \\
\hline
\end{tabular}

Elaboración propia a partir de listas de confirmados.

En 1724 hubo otra confirmación de solo 24 niños y niñas, apadrinados por el licenciado Pedro de Monte, presbítero lucense allí residente; en 1737 fue padrino otro presbítero, don Sebastián Pájaro, de Foxás; en 1748 confirmó el arzobispo Gil Taboada, actuando como padrino don Juan Antonio Moreira, su secretario personal. En mayo de 1774 el auxiliar Fondevila administró el sacramento a 87 mujeres y 79 hombres, de los que varios estaban casados o eran viudos. En 1786, Malvar confirmó a 119 solteros y Vélez en 1831a 79 matrimonios acompañados por sus hijos, criados y expósitos; de 261 hombres y 223 mujeres, eran adultos un 32,9\%, y de todos fueron padrinos don Manuel de Valderrama y su esposa, vecinos de Santiago ${ }^{38}$.

37. AHDS, P022610 y P022611.

38. AHDS, P022680 y P022681. 
OFELIA REY CASTELAO Y RUBÉN CASTRO REDONDO

EL SACRAMENTO OLVIDADO: LA CONFIRMACIÓN

EN LA ARCHIDIÓCESIS DE SANTIAGO, FINES DEL XVI A 1833

Para terminar, indicamos que algunos supuestos de los textos normativos aparecen de forma extraordinaria. Por ejemplo, en el concilio de Borromeo en Milán, se mandaba que «se le mude el nombre a los que le tuvieren ridículo, torpe y... no fueran nombres de christianos» como «los Julios, Pompeyos y otros nombres gentiles», y mandaba ponerles el «nombre de algún santo» ${ }^{39}$, lo que aprovechó la famosa beata Flavia Antonia Pereira do Campo, bautizada en 1700, para pasar a ser María Antonia, según ella misma relata en su biografía; en A Coruña se han detectado cambios de nombre en los márgenes de las partidas de bautismo (Nogueira, 2003: 256). Otra situación poco frecuente fue la confirmación de «herejes»: en la catedral compostelana en 25-2-1724 un hombre de 35 años, «de la secta mahometana y natural que dijo de la ciudad de Nazaret» fue bautizado por el provisor, actuando como padrino don Manuel Arroyo Herrero y Esgueva, sobrino del arzobispo, y en marzo fue confirmado por este llevando por padrino al jesuita Ignacio de Soto; en 20-4-1733 se repite el caso con Miguel, calvinista suizo, de 36 años, confirmado por el arzobispo al día siguiente del bautizo, y en 30-3-1779 Nicolás José Hemberris, sueco «hereje luterano» (Rey y Barreiro, 2014: 209-239).

\section{PADRINAZGO Y MADRINAZGO DE CONFIRMACIÓN}

El concilio de Trento en 1563 estableció que en la confirmación tendría que haber un padrino que, simbólicamente, tocaba a los apadrinados durante la ceremonia, y que por ello generaba el mismo parentesco espiritual que el bautismo, afectando «al confirmado, al padre y madre de éste, y a la persona que le tenga», sin precisar más. En el catecismo de Pío V, como vimos, se le encomendaba la formación de los apadrinados «porque si los luchadores necesitan de alguno que con arte y destreza les enseñe en qué manera podrán herir y matar al contrario, salvándose a sí mismo, ¿cuánto mayor necesidad de maestro y director tendrán los fieles?» ${ }^{40}$, aunque esa misión fue puesta en duda por varios de moralistas ya citados, que también discrepaban en el modelo de padrinazgo.

El pontifical romano admitía todo lo más un padrino para dos personas. Según algunos autores fue Carlos Borromeo en el famoso V concilio de Milán quien impuso un padrino para los varones y una madrina para las mujeres. El jesuita Busembaum escribió que «so culpa grave se requiere Padrino y ese ha de ser uno solo», además de estar confirmado, pero señala la falta de acuerdo sobre si podía serlo el del bautismo, o un monje, y aseveraba que no contrae «obligación de instruir al confirmando, sino solo parentesco» ${ }^{41}$. Diana estaba de acuerdo en esto y en que no importaba

39. Luis Muñoz, Vida de san Carlos..., p. 838.

40. Catecismo..., p. 189.

41. H. Busembaum, op. cit. p, 34 . 


\section{OFELIA REY CASTELAO Y RUBÉN CASTRO REDONDO \\ EL SACRAMENTO OLVIDADO: LA CONFIRMACIÓN \\ EN LA ARCHIDIÓCESIS DE SANTIAGO, FINES DEL XVI A 1833}

si era hombre o mujer, pero negaba que pudiera serlo el de pila ${ }^{42}$; Larraga (1706) y Echarri (1728) hablan solo de padrino, y lo mismo los autores de dos manuales compostelanos muy usados en la diócesis, el licenciado Manero (1665), quien recomendaba solo un padrino para el bautismo y para la confirmación, y el franciscano fray Antonio Barbeito (1726) que «debe ser uno solo» y «que no puede ser el del baptismo» ${ }^{43}$. En fin, como todo en este sacramento, se dejaba abierto.

Los sínodos de Santiago recogen la normativa: el de 1576 indica a los párrocos que debían informar al padrino de que contraía parentesco y el de 1746 de Gil Taboada añade que "no se comunica del marido, que fue padrino, a la mujer que no fue madrina; ni de la mujer que fue madrina, al marido que no fue padrino» ${ }^{44}$, es decir, podía haber padrino o madrina o ambos. No sabemos si se tomó de Borromeo o de Lambertini. En las instrucciones de este se recuerda la necesidad de padrinos porque así lo requieren decretos y teólogos, y su obligación de preparar «para la pelea» a sus apadrinados, por eso tenían que estar confirmados. De forma más práctica, ordenaba que ellos no podrían apadrinarlas a ellas, ni las madrinas a ellos, pero, para «obviar la cognación espiritual el uso permite ya que el uno mismo sea padrino de todos los varones y una madrina para todas las hembras»; tampoco admitía que los jóvenes pudieran apadrinar a los viejos, y no podrían serlo ni padre ni madre, pero no dice cómo debía procederse en su selección o a quién correspondía.

La normativa y los moralistas se inclinaban por solo un padrino, mejor todavía si era un eclesiástico, en un territorio de fuerte endogamia como lo era la Galicia occidental, tanto en el matrimonio como en el padrinazgo bautismal, ya que se evitaba incrementar el parentesco espiritual. Así pues, hasta 1774 hubo en todos los casos un único padrino para todos los confirmandos, en general clérigos de la parroquia o párrocos de las vecinas, y en las ciudades, canónigos u otros capitulares, o bien hombres del círculo de los prelados. Fue el arzobispo Bocanegra quien introdujo el doble padrinazgo, en 1774, al poco de llegar, y lo hizo en A Coruña, retrasándolo en Santiago, quizá para eludir problemas con el clero de la ciudad, siempre dispuesto a crearle conflictos por nimiedades.

Como dijimos, Bocanegra dio lustre y brillo a la ceremonia y esto dio atractivo social al hecho de figurar como padrino o madrina. Ese atractivo radicaba en que, a diferencia del bautismo, era oficiada por el arzobispo o su obispo auxiliar, rodeados de numeroso clero y de componentes de su corte y familia, y era colectiva, de modo que no había un protagonista único, como en el bautizo, ni doble, como en el matrimonio, sino que muchas veces se reunía a personas de más de una

42. A. Diana, op. cit., p. 588 .

43. Domingo Manero, Diffiniciones Morales, Santiago, J.B. González, 1665, p. 24. Fray Antonio Barbeiro, Grano de la Theologia Moral, Santiago, Aldemunde, 1726, p. 390.

44. Constituciones Synodales del Arzobispado de Santiago, Santiago, Aguayo, 1747, p. 78. 
OFELIA REY CASTELAO Y RUBÉN CASTRO REDONDO

EL SACRAMENTO OLVIDADO: LA CONFIRMACIÓN

EN LA ARCHIDIÓCESIS DE SANTIAGO, FINES DEL XVI A 1833

generación en un rito multitudinario en el que la atención se ponía en el prelado y en los padrinos, que lo acompañaban en el altar. No era, como el bautismo, una cita familiar sin fecha ni hora previsibles, sino pública y anunciada, y a veces fuera de la iglesia parroquial, en templos amplios o lucidos. Así pues, confirmandos y padrinos no siempre eran vecinos ni respondían a la composición social de cada parroquia o de cada barrio: fuesen quienes fuesen los confirmandos, los datos reunidos revelan que padrinos y madrinas pertenecían a los grupos acomodados e influyentes o en ascenso, sobre todo en las ciudades.

En Santiago, en la parroquia de A Corticela se puede seguir este proceso. Allí se registraban los extranjeros, pero también una población local de cierto nivel. Dado el pequeño tamaño del templo, incrustado en la catedral, los confirmandos acudían a ceremonias celebradas en el monasterio de Antealtares, el convento de San Francisco, el colegio de la Compañía de María, en capillas como la de Ánimas, en otras parroquias, en el oratorio del arzobispo o en oratorios privados, etc., en días sucesivos y con diferentes padrinos. En la ceremonia de 25-3-1605, cada confirmando llevaba un padrino, por lo general el mismo para cada grupo de hermanos, y podía serlo de otros; en total se confirmaron 57 niños y niñas - varios con tratamiento de don o doña, pero también varios de padres desconocidos $-\mathrm{y}$ entre los padrinos aparecen el licenciado Ortega Torquemada, el canónigo Salinas, el cardenal Calle, don Diego de la Rúa, etc., es decir, miembros del clero catedralicio ${ }^{45}$. En 1614 actuó un solo padrino para todos y en 10-3-1641 el licenciado Bedulos; en 1732, don Eliceto de Zúñiga, caballerizo mayor del arzobispo y en 1776 el músico italiano don Buono Chiodi, maestro de capilla de la catedral.

En las parroquias compostelanas aparecen madrinas desde 1787, aclarando los párrocos que lo eran para las mujeres y el padrino para los hombres.Dado que solían hacerse varios actos en varios días, se multiplicaban las oportunidades de lucimiento social de los padrinos. Estos eran todos notables locales: $20,3 \%$ hidalgos y nobles titulados, $8,1 \%$ militares, $6,1 \%$ políticos locales y el resto, comerciantes; solían ser matrimonios, pero aparecen otros parentescos o no había relación cuando el padrino era eclesiástico o estaba soltero, y rara vez se repetían, a diferencia de A Coruña. Las primeras madrinas fueron doña Felisa Pichini, mujer del músico don Pascual Pichini, y el padrino lo fue don Félix Pérgamo, compañero de su marido en la orquesta de la catedral, y en 1799, al lado del fiscal eclesiástico don Joaquín García Quiñones, lo fue doña Petra María Sanz, mujer del bohemio don Ignacio Kreibig, titular de una importante compañía comercial (Barreiro, 2000: 35-66). Las nobles con título y con casa abierta en la ciudad estuvieron representadas por la marquesa de Santa Cruz de Ribadulla en 1814, acompañada del canónigo don José Estampa.

45. En Valladolid eran eclesiásticos, comisarios de la Inquisición, personal de la familia episcopal (García, 2019: 55). 
OFELIA REY CASTELAO Y RUBÉN CASTRO REDONDO

EL SACRAMENTO OLVIDADO: LA CONFIRMACIÓN

EN LA ARCHIDIÓCESIS DE SANTIAGO, FINES DEL XVI A 1833

En la ciudad había un destacamento militar y por eso en 1819 el cardenal don Pablo Grandona hizo pareja con doña Rafaela Valenzuela, mujer del teniente coronel don Domingo Miñambres. En 1825, el coronel don Pedro Vélez, de la familia del arzobispo Vélez, y doña Antonia de Sanmamed, su esposa, actuaron en una ceremonia en la que se confirmaron varios parientes suyos; don Francisco María de Castilla, capitán de ingenieros, y doña Josefa Lobato, mujer de coronel de ese cuerpo; y otro matrimonio de alcurnia y en ascenso, el del brigadier de infantería y señor de la casa de Rial, don José Ozores, y doña Antonia Valderrama, que heredarían la casa de Rubiáns. Finalmente, don domingo Vales, fiscal de la Real Audiencia de Galicia, con doña María de los Dolores Herce - de familia coruñesa de abolengo, la de don Diego de Herce, colaborador de los liberales-. En Santa María y San Benito, la primera madrina, también 1787, fue la mujer del regidor don Pedro Varela Fondevila, doña María Manuela Baamonde: él era hermano del obispo auxiliar y ella quizá de la familia del comerciante don Tomás Vaamonde: apadrinaron a 750, destacando los cuatro hijos del conde de Priegue. En 1799 solo lo fue el fiscal Quiñones y en 1814, don Javier Losada y doña Inés Múzquiz, de la familia del arzobispo, en un acto en el palacio arzobispal para solo ocho confirmandos, mientras que al conde de Maceda y a doña María de Fernán Núñez, condesa de Ribadavia, se les reservó el honor de una confirmación masiva - 360 niños y niñas - en la magnífica iglesia del monasterio de San Martín Pinario.

Mucho más interesante es el caso de A Coruña, en donde Bocanegra impuso el modelo del padrinazgo doble ya en 1774, para implicar a los grupos emergentes. Al principio, por prudencia en la innovación, se combinó a un eclesiástico, don Ignacio Viadé, canónigo de la colegiata, con una madrina, doña María Riazos, de la familia del regidor don Nicolás Riazos, en una ceremonia multitudinaria en la colegiata. En 1779, el mismo canónigo estuvo acompañado por doña María de España, esposa del polígrafo e ilustrado don José Cornide, académico de la Real Academia de la Historia, y que formaba parte del concejo compostelano en los incidentes a la llegada del prelado. En 1795 el arzobispo Malvar delegó en el obispo de Puerto Rico don Francisco de La Cuerda, de paso en A Coruña en su regreso tras renunciar a aquel destino poco antes. Entre el 8 y el 15 de julio presidió 21 confirmaciones en la colegiata, lo que permitió paseíllo de padrinos importantes: en la primera, marcando estilo, don Mariano Colón de Larreategui, duque de Veragua, y doña Nicolasa Cerezo, mujer del regente de la Real Audiencia, don Vicente Peñuela, que volvieron a actuar a los pocos días. Luego, el capitán de la Armada don José Rodríguez acompañado de doña María Fonseca y Paz, esposa del coronel don Francisco Viedma, y numerosas parejas en las que ellos y ellas llevaban los apellidos de activos comerciantes coruñeses - Aldao, La Sota, Del Llano, Tavanera, etc. - , de miembros del Consulado o de la administración, y de hidalgos residentes en la 
OFELIA REY CASTELAO Y RUBÉN CASTRO REDONDO

EL SACRAMENTO OLVIDADO: LA CONFIRMACIÓN

EN LA ARCHIDIÓCESIS DE SANTIAGO, FINES DEL XVI A 1833

ciudad (Alonso 1986; Mariño 2009) ${ }^{46}$. El arzobispo Vallejo mantuvo el mismo criterio, de modo que en la macro-ceremonia de 1798 en la parroquial de San Nicolás fueron padrinos don Ramón Torrado, rico hombre del comercio, y doña Francisca de Osorio, repitiendo a los pocos días; en ese año actuaron también doña Josefa del Llano y doña Mercedes de La Calleja, de familias comerciantes relacionadas entre sí. En general se trata de un perfil muy diferente al de Compostela por el decisivo peso del sector mercantil.

Ya en el siglo XIX, es frecuente la repetición de padrinos, siempre de las elites coruñesas e incluso foráneas, a pesar de que la crisis del comercio con América había arruinado a muchas familias. El 5 y 6 de abril de 1806 Múzquiz confirmó a novecientas personas apadrinadas por don Dámaso Rollo y doña Juana Fernández, mujer de don Miguel de La Lastra - de familias destacadas -; en 10-4-1810 confirmó en la colegiata a 574 por don Gonzalo Mosquera - miembro del Consejo de Administración creado para el gobierno local durante la Independencia - y su mujer doña Joaquina Ribera, y el 13 en el convento de Santa Bárbara, don Jacobo Becerra, auditor de Marina, y doña Jacinta Valladares, su mujer, y doña Juana Fernández de la Barca, de una activa familia mercantil.

En la primera y larga campaña de fray Rafael Vélez, del 23-10-1825 a 22-1-1826, la política se cruzó en la selección de padrinos, al reducirse la nómina a sus afines. Debe tenerse en cuenta que, salvo el alto clero y hombres del ejército, apenas hubo en A Coruña defensores radicales del absolutismo vinculados a la burguesía, aunque en 1825 participaban como regidores en el ayuntamiento de la restauración absolutista. Así pues, el grupo mercantil siguió presente, pero a través de menos personas: en ocho ocasiones fueron padrinos don Miguel Donato y su hija Leocadia: él era natural de Xátiva, comerciante con La Habana, armador y corsario. Varias veces lo fue don Luis Rueda, un absolutista que ocupaba el cargo de gobernador político y militar de la plaza y presidente del regimiento municipal, acompañado de su esposa doña Jacoba Gil Taboada, tocándoles ser padrinos de vástagos de importantes familias. Y miembros de familias comerciantes y emparentadas como los Torres Moreno, originarios de la Sierra de Cameros, y Fernández de la Barca: don Andrés Torres Moreno, burgués, regidor y mayor contribuyente de A Coruña y su mujer doña Rita Arias de la Barca - hija de don Ceferino Arias, regidor, procurador de la ciudad, comerciante, capitalista y mayordomo de la colegiata $-\mathrm{y}$ otro rico

46. Don Ignacio Aldao, regidor en 1798 y doña Lorenza Márquez; don Pedro Taboada y doña Angela Corral; doña Josefa Pardo; presbítero Lucas Vitori; don Angel A. Henry con doña Ángela Tavanera; don Ignacio Alloza con doña María Márquez; don juan Padilla; don Ignacio Calviño; don Antonio de Pazos; don Bartolomé Carril con doña Pilar Aldao; don José Alvarez de Lamas con doña Ana de La Sota; don Pedro del Llano con doña Rosa Romay; don Diego Calvo con doña Francisca Pardo; don Juan Araújo con doña $\mathrm{M}^{a}$ Antonia Verasain; don Roque Sanjurjo; don Simón Renato con doña Isabel Castro. 
OFELIA REY CASTELAO Y RUBÉN CASTRO REDONDO

EL SACRAMENTO OLVIDADO: LA CONFIRMACIÓN

EN LA ARCHIDIÓCESIS DE SANTIAGO, FINES DEL XVI A 1833

capitalista y regidor, don Martín Torres Moreno - mayordomo de la parroquia de San Jorge - y la mencionada doña Josefa Fernández de la Barca. Los militares aparecen representados por el coronel don Antonio Soto Alfeirán y su esposa, doña Juana Morillo, hermana del héroe de la Independencia, Pablo Morillo.

En 1827, el obispo de Lugo, Hipólito Sánchez Rangel, con licencia del arzobispo, ofició tres ceremonias en el convento de san Francisco en las que se confirmaron solo diez personas, apadrinadas por don Domingo Miñambres, teniente coronel del regimiento de Betanzos y doña Dolores Sequeiros, soltera, y don Pedro Celestino Romero, médico titular de A Coruña. De 29-12-1828 a 20-2-1829 estuvieron Vélez y su auxiliar San Lúcar en A Coruña, prodigándose por parroquiales y conventos y de nuevo entre los padrinos está Luis Rueda, pero solo para apadrinar a su cuñado don Francisco Sangro y Páramo - que sería alcalde de la ciudad en la década moderada -, para que, junto con su mujer, doña Manuela Rueda, pudiesen actuar como padrinos en las ceremonias presididas por el auxiliar en el convento de santo Domingo. De forma destacada aparece don Bartolomé Casas Díaz, comerciante, tratante de esclavos negros y uno de los mayores contribuyentes de la ciudad, con su cónyuge, doña Rita de la Barca, al menos en seis ceremonias, en las que apadrinaron a varios hijos de familias importantes, y de nuevo aparecen don Ramón Moreno y su mujer. Se incorporan a la lista los hermanos don Carlos y doña Juana Arce en dos ocasiones. En 1829 y 1833 actuaron don Francisco J. Oms, marqués de Casteldosrius, y su mujer, doña Teresa Senmenat; él, ex gobernador de Andalucía, de tendencia liberal, estaba por entonces preso en el castillo de San Antón, del que salió en 1833 para acogerse a la amnistía. En ese año fue padrino don Antonio Ubach, regente de la Audiencia para solo dos confirmandos: eran los hijos de doña Josefa Villar y de don Pablo Morillo, nuevo capitán general de Galicia desde ese año en el que el gobierno volvió a A Coruña. Por cierto, sería la autoridad encargada de llevar a juicio a Vélez y a su auxiliar (Barreiro, 1986: 419).

No se puede decir que las familias destacadas recurrieran a confirmaciones individuales, porque en muchas ocasiones estas podían responder a actos consecutivos. No obstante, sí hubo casos de trato diferenciado, en lugares especiales y con padrinos de nivel igual o superior al de las familias de los confirmandos. Así, por ejemplo, en 10-3-1641, en el compostelano monasterio de Antealtares el obispo de Ourense confirmó a doña Francisca, hija de doña María de Aguiar, que tuvo padrino para ella sola, Nicolás de Castro. En 28-8-1799 fue confirmada en el colegio de la Compañía de María de Santiago doña María del Carmen, hija del comerciante coruñés y miembro del Consulado, don Pedro Mendinueta y de doña Nicolasa Sáez, siendo madrina doña Rosa Freire ${ }^{47}$. En 22-4-1820 el obispo de Ourense confirmó en el monasterio de Antealtares a una joven apadrinada por el padre Manuel Ozalla

\section{AHDS P08870.}


OFELIA REY CASTELAO Y RUBÉN CASTRO REDONDO

EL SACRAMENTO OLVIDADO: LA CONFIRMACIÓN

EN LA ARCHIDIÓCESIS DE SANTIAGO, FINES DEL XVI A 1833

y por Luisa Ferreira. Sin duda eran educandas o novicias. En 1721, en Sigrás, cerca de A Coruña, el arzobispo Salcedo confirmó solo a María Teresa, hija del receptor de la Real Audiencia don Lorenzo de Seixas y de doña Ana Prego de Montaos, siendo padrino el presbítero Francisco de Otero. En 18-2-1827 Vélez confirmó en el convento de las capuchinas de A Coruña a dos hijos de Santiago de Blasco y doña Mercedes Bermúdez, de los que fueron padrinos un hermano y una hermana de los confirmandos; y a la hija de don Miguel y doña Vicenta Marques, de la que fue madrina doña Dolores Sequeiros. Este prelado repitió esas ceremonias exclusivas en 1829 para los tres hijos de don José María Bermúdez y doña Josefa Ibáñez, de don Gaspar Virués y doña Rita de la Barca, etc. Ignoramos si estas ocasiones daban lugar a fiestas familiares, pero sin duda tenían un sentido de diferenciación social.

En las ciudades pequeñas y en las villas encontramos sobre todo hidalgos y algunos nobles titulados: por ejemplo, en Betanzos, en 1828, actuaron los condes de Vigo y vizcondes de Bañobre, siendo él don Joaquín Tenreiro, libertador de Vigo en la guerra de Independencia, y la marquesa de Vilagarcía actuó en la villa de Carril. En el rural, antes de 1786 todos los padrinos eran clérigos. Desde entonces hubo padrinos y madrinas que en todos los casos llevaban tratamiento de don o doña; eran matrimonios la mayoría de las veces y el resto eran parientes o carecían de relación. La primera madrina, quizá para marcar la novedad, se localiza cerca de Santiago, en Santa Cruz de Ribadulla, en 1786: doña Teresa Armada, de la familia del marqués de Santa Cruz. En general, como hemos visto en algunos ejemplos citados, eran notables de las parroquias, pero en más de una ocasión se declararon vecinos de ciudades, de lo que se deduce que tendrían casas o intereses en el campo.

\section{CONCLUSIONES}

La confirmación es el sacramento más olvidado por los historiadores - no tanto por los teólogos -, lo que refleja el descuido en su cumplimiento en la Edad Moderna. La carencia de voluntad de cumplirlo por parte de los obispos, los únicos oficiantes posibles, derivaba de que no era necesario para la salvación, pero también de las dificultades de visitar todas las parroquias de las diócesis cada poco tiempo para que todos los fieles fuesen confirmados. La desidia se advierte también en el clero parroquial, que no explicaba ese sacramento a los feligreses - quizá porque los propios curas no lo entendían-, de modo que no preparaban bien las ceremonias, no llevaban libros de registros de los confirmados, no anotaban a los padrinos, etc. Claro está, la actitud de unos y otros se tradujo en la de los fieles, que no acudían a confirmarse o no enviaban a sus hijos a confirmar. En la archidiócesis de Santiago, mediante la consulta de cientos de listas de confirmación, hemos podido comprobar que fue así durante buena parte de la Edad Moderna, tanto por la falta de voluntad 
OFELIA REY CASTELAO Y RUBÉN CASTRO REDONDO

EL SACRAMENTO OLVIDADO: LA CONFIRMACIÓN

EN LA ARCHIDIÓCESIS DE SANTIAGO, FINES DEL XVI A 1833

o de capacidad física de los arzobispos como por la extraordinaria dificultad de visitar una diócesis enorme en tamaño, población y parroquias.

Pero lo más importante a efectos religiosos es que en el siglo XVIII y en especial en su última parte, así como en el primer tercio del XIX, la confirmación se convirtió en un instrumento muy útil a los arzobispos para reforzar su imagen, personándose en ciudades, villas y feligresías rurales, o enviando a sus obispos auxiliares, e implicando en el ceremonial a padrinos y madrinas extraídos de los grupos poderosos tradicionales - nobles titulados, hidalgos - y sobre todo, de la burguesía mercantil urbana. En ceremonias multitudinarias cada vez mejor organizadas, los prelados dejaban claro su poder como obispos frente al cabildo catedralicio compostelano y al clero diocesano, como señores del mayor señorío gallego - lo que incluía a Compostela - y como autoridad eclesiástica frente a la autoridad civil de la capital administrativa de Galicia, A Coruña. La predicación por parte de los prelados o, como hemos visto, de misioneros llamados ad hoc, colaboraban en esa campaña de imagen. Todo lo cual se concitó entre fines del XVIII y 1833, en la crisis del Antiguo Régimen, cuando el cuestionamiento del señorío y de las rentas arzobispales, suprimidos en las Cortes de Cádiz y en el Trienio, debilitaron la posición de los arzobispos de Santiago.

Desde el punto de vista de los fieles urbanos y rurales, no hay testimonios de cómo recibían la confirmación, sino solo la percepción por parte de las autoridades eclesiásticas sobre una indiferencia generalizada. La causa de esta sería la falta de compensación por recibir ese sacramento, ya fuera en términos de salvación o de un beneficio religioso visible como, por ejemplo, el perdón - al contrario, había que ir perdonado-, o, al menos comprensible, como lo sería la concesión de indulgencias, y seguramente también por la falta de un sistema de punición de su incumplimiento. De ahí los datos expuestos sobre el absentismo cuando las ceremonias se celebraban fuera de las respectivas parroquias y exigían un traslado y una inversión de tiempo, y de numerosas personas, e incluso familias, que no acudían aun celebrándose en el propio lugar de residencia. El hecho de que en el ámbito rural las visitas de los prelados se produjeran en los meses con mayor carga de trabajo y de desplazamientos temporeros fuera de Galicia sin duda contribuyó a esas ausencias.

La irregularidad de las visitas de los arzobispos o de sus auxiliares y el abanico de edades de los confirmandos no favorecieron que la confirmación actuase como un rito de paso, como sí lo era la primera comunión, cuya fecha era dada por la edad, los siete años por lo general. Ahora bien, la progresiva vigilancia y, sobre todo, la creciente espectacularidad de las ceremonias, en presencia de los arzobispos o de los obispos - algo realmente extraordinario fuera de Compostela-, pudo atraer a cada vez más asistentes, sin que se convirtiera en una fiesta familiar, salvo quizá entre los grupos de élite. Todo indica que esta dimensión festiva de la confirmación quizá fue utilizada por los arzobispos de fines del Antiguo Régimen para competir 


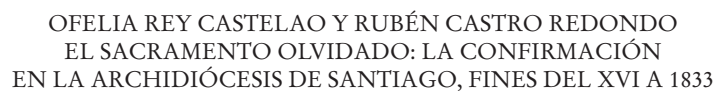

con las celebraciones y entretenimientos civiles que, en los núcleos urbanos, A Coruña en especial, ganaban en importancia de la mano de los poderes municipales y de las burguesías.

\section{BIBLIOGRAFÍA}

ALONSO ÁLVAREZ, L. (1986). Comercio colonial y crisis del Antiguo Régimen en Galicia (1778-1818). A Coruña: Xunta de Galicia.

BARREIRO FERNÁNDEZ, X. R. (1986). Historia de la Ciudad de A Cornña. A Coruña: La Voz de Galicia.

BARREIRO FERNÁNDEZ, X. R. (2000). «A burguesía compostelá (1760-1808), unha base de datos». Sémata, 12, 35-66.

BARREIRO MALLÓN, B. (1990). «El clero de la diócesis de Santiago a través de las visitas pastorales, visitas ad limina, registros de licencias ministeriales y concursos de curatos». Compostellanum, 3-4, 489-515.

BARREIRO MALLÓN, B. (2002). «La diócesis de Santiago en la época moderna». En J. García Oro (coord.), Iglesias de Santiago de Compostela y Tuy-Vigo. Madrid: BAC, 177-408.

BÉTHENCOURT MASSIEU, A. (1999). «Fuerteventura ante la Ilustración. La visita pastoral del obispo Tavira en 1792». Anuario de Estudios Atlánticos, 45, 281-341.

CARR, E. (ed.) (2007), La Cresima.Roma: Centro Studi Sant'Anselmo.

CASTRO MONTOYA, J. (2011). «La visita del obispo de Calahorra, don Andrés de Porras y Temes a Motriku en 1763». Kalakorikos, 16, 255-268.

COUSELO BOUZAS, J. (1927). Fray Rafael Vélez y el seminario de Santiago. Santiago: Seminario.

DEDIEU, J. P. (1979). ««Christianisation» en Nouvelle Castille: catéchisme, communion, messe et confirmation dans l'archevêché de Tolède, 1540-1650». Mélanges de la Casa de Velázquez, 15, 261-294.

DELUMEAU, J. (dir.) (1987). La Première communion: quatre siècles d'histoire. Paris: Desclée.

DOMATO BÚA, D. (coord.) (2017). Catálogo de impresos del Archivo Histórico Diocesano de Santiago, ss. XVI-XVIII. Santiago de Compostela.

GARCÍA CORTÉS, C. (1982). «El arzobispo compostelano fray Rafael de Vélez (17771850)». Hispania sacra, 70 (34), 355-387.

GARCÍA FERNÁNDEZ, M. (2019). Los caminos de la juventud en la Castilla moderna. Madrid: Sílex.

GARCÍA HOURCADE, J. J. e IRIGOYEN LÓPEZ, A. (2006). «Las visitas pastorales, una fuente fundamental para la historia de la Iglesia en la Edad Moderna». Anuario de Historia de la Iglesia, 15, 293-304.

HEYWOOD, C. (2018). Childhood in Modern Europe. Cambridge: Cambridge U. Press. JAÉN SÁNCHEZ, P. J. (2011). «Un modelo de visita pastoral. Ayna (1766)». Al-Basit, $56,99-126$. 


\section{OFELIA REY CASTELAO Y RUBÉN CASTRO REDONDO \\ EL SACRAMENTO OLVIDADO: LA CONFIRMACIÓN \\ EN LA ARCHIDIÓCESIS DE SANTIAGO, FINES DEL XVI A 1833}

LÓPEZ FERREIRO, A. (1911). Historia de la S. A. M. I. de Santiago de Compostela. Santiago: Seminario.

MARIÑO BOBILLO, Ma . C. (2009). La Coruña bajo el reinado de Fernando VII.A Coruña: UNED.

MELLOT, J. (1987). «Rite de passage et fête familiale, rapprochements». En J. Delumeau (dir.), La Première communion: quatre siècles d'histoire. Paris: Desclée, 171-196.

MORGADO, A. (2008). La Diócesis de Cádiz: De Trento a la Desamortización. Cádiz: Universidad.

NOGUEIRA SANTIAGO, P. (2003). La Corogne à l'Époque Moderne (1517-1800). Contribution à une étude de la population. Tesis inédita, Université Paris IV ParisSorbonne.

PÉREZ GARCÍA, J. M. (1979). Un modelo de sociedad rural de Antiguo Régimen en la Galicia costera: la peninsula del Salnés. Santiago: Universidad.

PÉREZ GARCÍA, R. (2000). «Visita pastoral y confirmación en la archidiócesis de Sevilla, 1600-1650». Historia Instituciones Documentos, 27, 205-233.

REY CASTELAO, O. (1981). Aproximación a la historia rural de la comarca de la Ulla, siglos XVII-XVIII. Santiago: Universidad.

REY CASTELAO, O. (2004). «¿Biografía o hagiografía? «Memorias breves» del arzobispo Don Francisco Blanco de Salcedo». En O. Rey Castelao et al., Cuatro Textos. Cuatro Contextos. Santiago: Universidad, 13-101.

REY CASTELAO, O. y BARREIRO MALLÓN, B. (2014). «Apadrinar a un pobre en la diócesis de Santiago de Compostela, siglos XVII-XIX». En Mª J. Pérez Álvarez y $\mathrm{M}^{\mathrm{a}} \mathrm{M}$. Lobo de Araújo (coords.), La respuesta social a la pobreza en la Península Ibérica durante la Edad Moderna. León: Universidad, 209-238.

RIBAS BRACONS, J. M. (1966). «Efectos jurídicos del sacramento de la confirmación»,Ius Canonicum, 6, 12, 403-439.

RODRÍGUEZ FERREIRO, H. (2004). O Morrazo en los siglos XVII y XVIII. Pontevedra: Diputación.

RODRÍGUEZ PAZOS, M. (1946). El episcopado gallego a la luz de los documentos romanos. Madrid: CSIC.

VÁZQUEZ VILANOVA, J. A. (2004) Clero y sociedad en la Compostela del siglo XIX. Santiago: CSIC.

VÉNARD, M. (ed.) (1997). L'Âge de raison (1620-1750): Histoire du christianisme, t. 9. París: Desclée. 
OFELIA REY CASTELAO Y RUBÉN CASTRO REDONDO

EL SACRAMENTO OLVIDADO: LA CONFIRMACIÓN

EN LA ARCHIDIÓCESIS DE SANTIAGO, FINES DEL XVI A 1833

Mapa 1. Confirmaciones en la archidiócesis de Santiago, 1599-1715

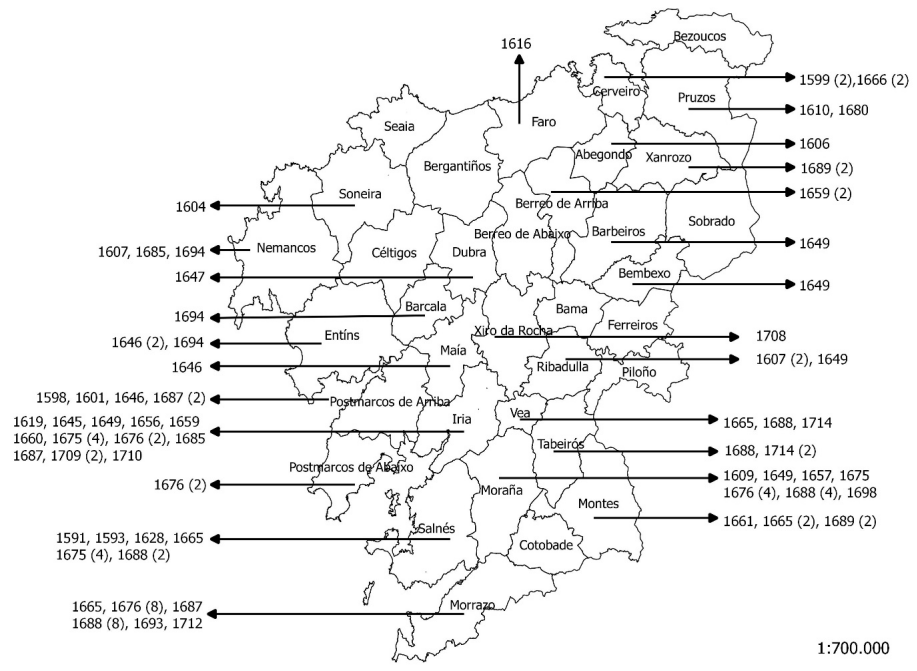

Fuente: Listas de confirmados AHDS

Mapa 2. Confirmaciones en la archidiócesis de Santiago, 1715-1820

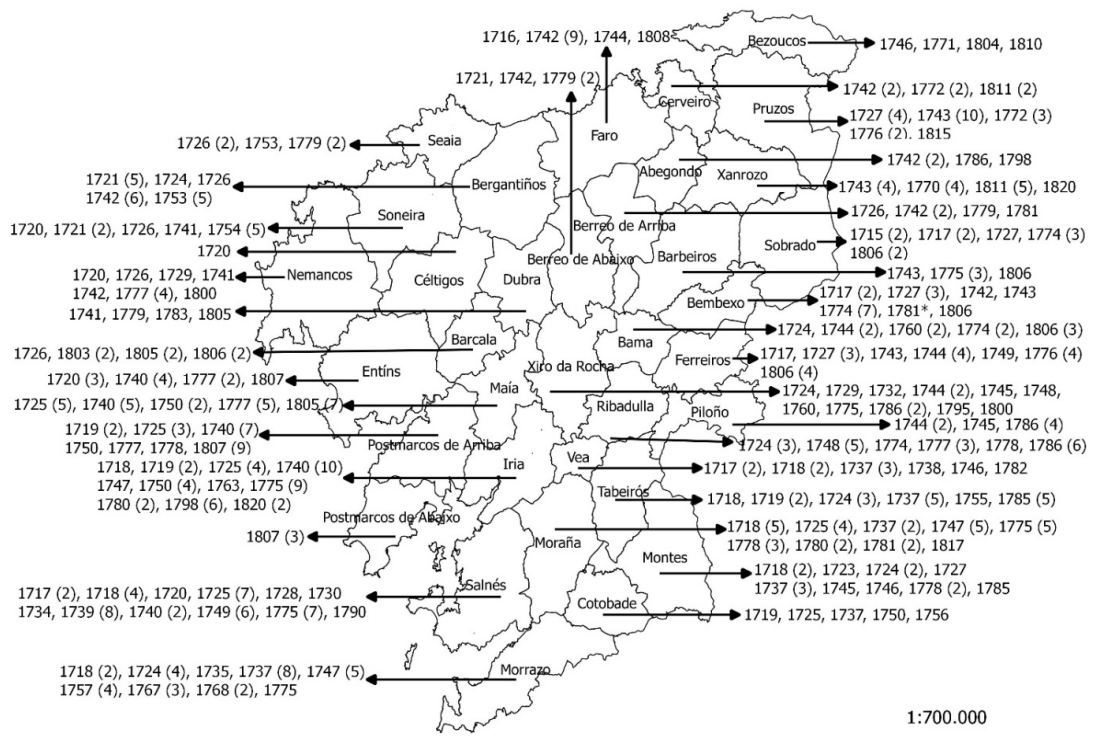

Fuente: Listas de confirmados AHDS.

Ediciones Universidad de Salamanca / @®@ఠ

Stud. his., H. ${ }^{a}$ mod., 41, n. 2 (2019), pp. 35-69 
OFELIA REY CASTELAO Y RUBÉN CASTRO REDONDO

EL SACRAMENTO OLVIDADO: LA CONFIRMACIÓN

EN LA ARCHIDIÓCESIS DE SANTIAGO, FINES DEL XVI A 1833

Mapa 3. Confirmaciones del arzobispo Vélez

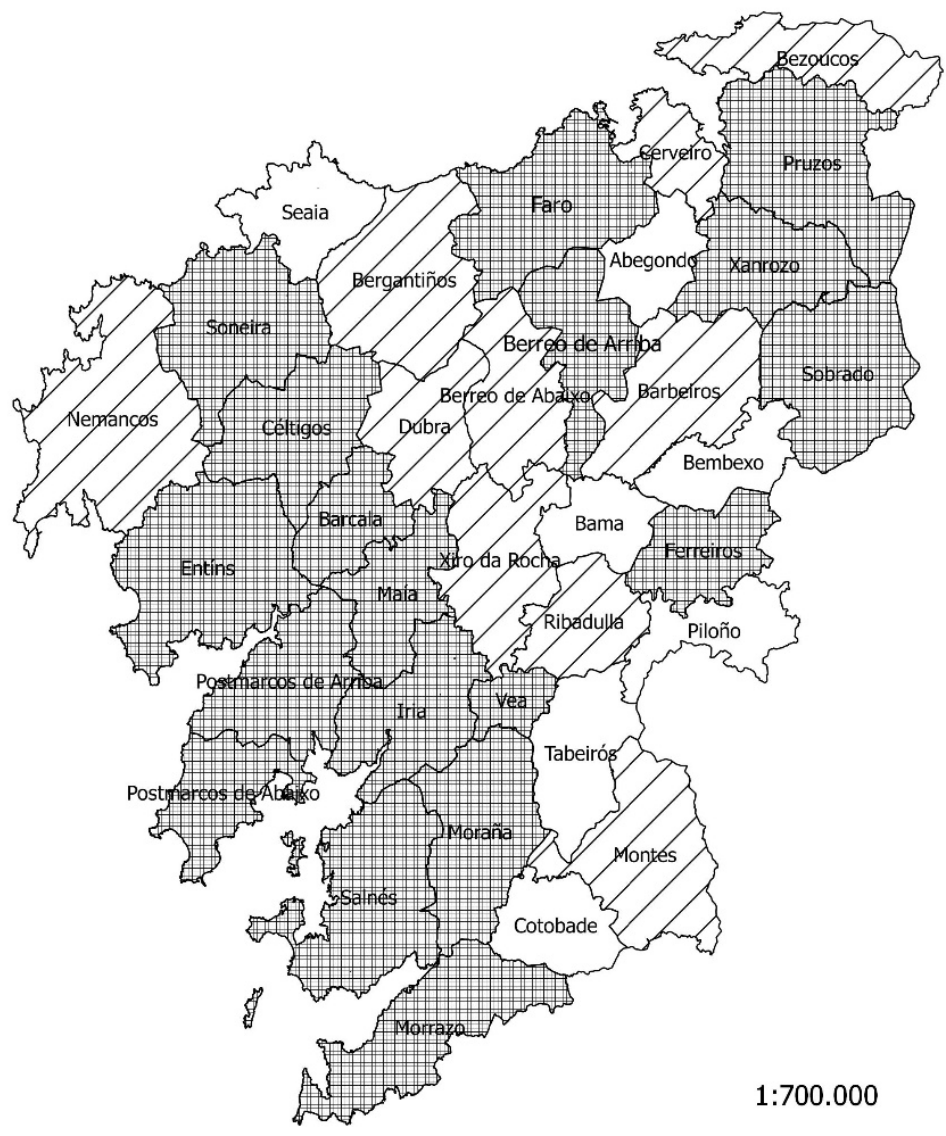

Gris: arciprestazgos con $+30 \%$ de parroquias con listas de confirmación Rayado: $15-30 \%$. Blanco, $-15 \%$

Fuente: Listas de confirmados AHDS 